\title{
Selection and Evaluation of Reference Genes for Quantitative Real-Time Reverse-Transcriptase PCR under Cold Stress in Eggplant (Solanum melongena L.) during Fruit Development
}

\author{
Jinkun Yang \\ Chinese Academy of Agricultural Sciences https://orcid.org/0000-0003-3854-9835 \\ Ying Zhang \\ Chinese Academy of Agricultural Sciences Institute of Vegetables and Flowers \\ Yong Lian \\ Chinese Academy of Agricultural Sciences Institute of Vegetables and Flowers \\ Yuhui Chen \\ Chinese Academy of Agricultural Sciences Institute of Vegetables and Flowers \\ Fuzhong Liu ( $\square$ Ifzcaas@126.com ) \\ Institute of Vegetables and Flowers, Chinese Academy of Agricultural Sciences
}

\section{Research article}

Keywords: Reference genes, expression stability, cold stress, eggplant

Posted Date: November 10th, 2020

DOI: https://doi.org/10.21203/rs.3.rs-79512/v1

License: () (i) This work is licensed under a Creative Commons Attribution 4.0 International License. Read Full License 


\section{Abstract \\ Background}

Eggplant (Solanum melongena L.) is a thermophilic vegetable, and its yield and quality are often affected by cold stress. Therefore, identifying the key genes and mechanisms of cold tolerance has become a significant topic in eggplant. qRT-PCR has been widely used to analyse gene expression patterns, and reliable reference genes are necessary for this technique.

\section{Methods}

To select and evaluate suitable reference genes for qRT-PCR, 18 candidate genes selected from transcriptome sequence data were subjected to analysis of their expression stability under natural cold and normal temperature conditions. Four commonly used programs (geNorm, NormFinder, BestKeeper and RefFinder) were used to determine the stabilities of these genes.

\section{Results}

The results showed that D5, D4 and D1 were the three most stable reference genes among the 18 genes. Then, D5, D4 and D1 were compared with commonly used reference genes. The results showed that D5 was still the most stable gene, followed by APRT, D4, and Actin was the least stable gene.

\section{Conclusion}

D5, APRT and D4 were recommended as a reference gene combination for gene expression normalization under cold stress and at normal temperature during fruit development. Our results provide a molecular foundation for further research on the cold tolerance mechanism of eggplant.

\section{Background}

Eggplant is one of the most popular vegetable crops in the world. Like many thermophilic vegetables, eggplant often fails to set fruit under cold stress, which seriously influences eggplant yield and quality [1]. Cultivating cold-resistant varieties is a cost-effective way to avoid heavy losses resulting from cold stress. However, the major gene(s) and molecular mechanism underlying low-temperature resistance in eggplant are unknown and need to be further studied.

Detecting gene expression abundance is a very important method for selecting candidate genes and researching molecular mechanisms. To analyse gene expression levels, many techniques, such as DNA microarrays, northern blot analysis, ribonuclease protection assays and quantitative real-time reverse-transcriptase PCR (qRT-PCR), have been widely used [2-4]. Of these techniques, qRT-PCR is the most commonly used to measure levels of gene expression because of its high sensitivity, accuracy, specificity, throughput capability and low cost $[5,6]$. When conducting a qRT-PCR experiment, it is necessary to select appropriate reference genes for normalizing target gene expression.

Reference genes, also known as housekeeping genes, are stably expressed across different developmental stages, tissue types and experimental conditions. In addition, an ideal reference gene should have expression abundances similar to those of target genes in all samples [7]. Genes that are commonly used as reference genes mainly include Actin, glyceraldehyde 3-phosphate dehydrogenase $(G A P D H)$, beta-tubulin (TUB), adenine phosphoribosyltransferase (APRT) and 18S ribosomal RNA (18S) [6]. However, many studies have shown that these reference genes have different expression levels across different materials [8,9], plant tissues and treatments $[10,11]$, which means that reference genes may not always be stable in practical experiments. Thus, it is necessary and important to select and validate reliable reference genes under different experimental conditions before conducting gene expression research. Some reference genes for eggplant have been reported. Based on screening for stable reference genes, alpha-tubulin (TUA) and elongation factor 1-alpha (EF1) were the most stable genes in all samples of Solanum aculeatissimum (including different tissues, plant growth regulator treatments, and abiotic and biotic stresses) [12]. Solanum melongena of elongation factor 1-alpha (SmEF1a) and Solanum melongena of thioredoxin (STTRX) were the most stable reference genes under high-temperature stress in eggplant 
[13]; further, geNorm identified SAND family protein (SAND) and TATA box binding protein (TBP) as the most stable gene combination, and NormFinder identified expressed sequence (Expressed) as the best reference gene during eggplant fruit development [14]. To date, however, no suitable reference gene has been selected for low-temperature conditions in eggplant.

Advances in molecular biology have made it possible to identify more stable and new genes as reference genes rather than traditional screening approaches for reference genes. In this study, 18 candidate reference genes from fruit (ovary) transcriptome datasets (unpublished data) were tested for their expression stabilities during fruit developmental stages under cold stress and normal temperature. Then, a stability comparison between the 3 most stable of the 18 candidate genes and commonly used reference genes was made. Our study aims to detect the most stable reference gene combination suitable for normalizing gene expression analysis during fruit development in eggplant under cold stress and normal temperature. This research can provide a basis for understanding eggplant cold tolerance mechanisms.

\section{Results}

\section{Screening and Analysis of Candidate Reference Genes Selected from Transcriptome}

The specificity of the primer pairs designed from the 18 candidate reference genes was detected using 3.0\% agarose gel electrophoresis, and each result showed a single band with the expected size (Figure 1). Furthermore, their qRT-PCR products also showed a single peak in the melting curve analysis (Figure 2).

From the calculation of standard curves, we found that the amplification efficiencies of these primers ranged from $81.05 \%$ (D3) to $99.90 \%$ (D11), and the correlation coefficients ranged from 0.9670 (D2) to 0.9998 (D6, D13) (Table 1). Thus, these primer pairs were reliable.

Gene transcript abundance is often represented by the $\mathrm{Ct}$ (Cycle threshold) value of the gene, which is negatively correlated with expression abundance: the higher the $\mathrm{Ct}$ value, the lower the expression level. Different genes had different $\mathrm{Ct}$ values across all the samples. The Ct values were visualized using a boxplot, and they varied from 13.02 to 27.19 . Compared with other genes, D5 had the highest expression level with an average Ct value of 14.33, whereas D18 had the lowest expression level with an average Ct value of 22.77 in these samples (Figure 3). In addition, the majority of these values were between 15.95 and 19.87. Detailed data are provided in Supplementary Table S1.

Four commonly used housekeeping gene selection tools, namely, geNorm, NormFinder, BestKeeper and RefFinder, were used to analyse the stability of the candidate reference genes. GeNorm, NormFinder and BestKeeper use Microsoft Excel as their operational platform, while RefFinder operates on a website.

In geNorm software, the stability of candidate reference genes is represented by their stability $(M)$ values. The threshold of $M$ was set as 1.5; a lower value of $M$ indicated a higher gene expression stability [4]. The average $M$ values calculated by geNorm under automated analysis are shown in Table 2. In all samples and under the condition of cold stress, D1 and D2 were ranked as the two most stable genes, with the lowest average $M$ values of these genes being 0.46 and 0.39 , respectively. D4 and D5 were the two most stable genes under normal temperature, with the lowest $\mathrm{M}$ value of these genes being 0.41 . In addition, D18 was the least stable gene in all sample groups, with $M$ values of $1.10,0.96$ and 1.04 , respectively.

The $V n / V n+1$ value was used to determine the optimal number of reference genes for accurate normalization. This measure recommends a $V$ score below 0.15 as ideal for a test system. If the value of $V n / V n+1<0.15$, then the optimal number of reference genes is $n$ [4]. In this study, the values of $V_{2} / V_{3}$ were less than 0.15 in all samples and under cold stress conditions, which suggested that two reference genes would be sufficient for gene normalization. However, under normal temperature conditions, $V_{2} / V_{3}>0.15$ and $V_{3} / V_{4}<0.15$, which meant that three reference genes would be necessary for gene normalization under these conditions (Figure 4). Because the proposed value (0.15) is not a strict cut-off value, whether two or three reference genes should be used for gene normalization will likely depend on the specifics of the experiment, and some previous reports have indicated that three reference genes are ideal for gene normalization [15-17]. As a result, we chose three reference genes in this study.

NormFinder is a model-based strategy that can identify the optimal normalization genes among a set of candidates. It can not only calculate the stability $\left(M_{1}\right)$ values of candidate genes and rank them according to these values but also incorporate intra- and 
intergroup variations for normalization factor calculations and thus directly estimate expression variation [18]. The expression stability values of the 18 candidate reference genes calculated by NormFinder are shown in Table 3. For all samples and normal temperature samples, D5 was the most stable gene, with $M_{1}$ values of 0.30 and 0.25 , respectively. For the samples exposed to cold stress, D4 was recommended as the best reference gene, with an $M_{1}$ value of 0.33 .

BestKeeper is another tool used to analyse the expression stability of candidate reference genes by calculating the coefficient of variation (CV) and standard deviation (SD). Since the Ct values were of the same order of magnitude and did not vary greatly in this study, the stability of the genes was compared according to the SD values. Any candidate genes with an SD greater than 1 should be excluded. The reference gene with the lowest SD was suggested as the most stable gene [19]. The values of SD calculated by BestKeeper are shown in Table 3. Obviously, D5 $(0.607,0.575)$ was the most stable gene under the conditions of all samples and cold stress. However, for the normal temperature samples, D10 (0.574) was the most stable gene, followed by D5 $(0.585)$. In addition, the SDs of D18 $(1.622,1.130,1.367)$ and D14 $(1.047,1.128,1.097)$ were greater than 1 in the three sample sets, which indicated that they should be excluded.

The rank orders of the eighteen tested genes generated by geNorm, NormFinder and BestKeeper showed some differences (Table 2, Table 3). To conduct a comprehensive evaluation, the web-based tool RefFinder was used to rank these genes based on their comprehensive ranking values $\left(M_{2}\right)$. RefFinder was developed to evaluate and screen reference genes from extensive experimental datasets. The tool integrates currently available major computational programs to compare and rank the tested candidate reference genes. According to the ranking values, D5 was the most stable gene, and D5, D4 and D1 were the 3 most stable genes under the three conditions for all samples, cold stress and normal temperature (Table 3).

\section{Stability Comparison Between the Screened Candidate Reference Genes from the Transcriptome and Commonly Used Reference Genes}

A further stability comparison between our selected stable reference genes (D5, D4, D1) and commonly used reference genes (Actin, GAPDH, TUB, APRT and $18 S$ ribosomal RNA) was made to confirm the necessity of selecting reference genes through the same methods (Supplementary Table S2.). The results are shown in Table 4. In general, D5 still shows the best stability (except in all samples calculated by BestKeeper). However, the stability comparison results obtained from geNorm and NormFinder indicated that $A P R T$ was more stable than D4 and D1 with lower $M$ and $M_{7}$ values. Different stability ranking orders could be found from the result of BestKeeper, in which D5, D4 and D1 were more stable than APRT under cold stress and normal temperature but least stable than $A P R T$ in all samples. Thus, a further comprehensive stability analysis was performed by RefFinder, and the results showed that D5, $A P R T$ and D4 were the top three stable reference genes under cold stress and across all samples, whereas D5, APRT, and GAPDH were the top three stable reference genes under normal temperature. It is worth noting that Actin showed the lowest stability in all experimental conditions, which suggested that commonly used reference genes might not be stable in some practical experiments. Considering the comparison results and the previous selection work synthetically, we finally recommended D5, APRT, and D4 as a reference gene combination in eggplant fruits under cold and normal temperatures.

To illustrate that reference genes influence qRT-PCR results in eggplant fruit, the expression level of the eggplant methionine sulfoxide reductase A gene ( $\mathrm{SmMsr} A$ ) was analysed at cold and normal temperatures by using the three most stable reference genes (D5, APRT and D4), a combination of the top three most stable reference genes (D5+APRT+ D4) and the worst reference gene (Actin) as reference. SmMsrA, which was cloned by our research team, might be related to resistance during fruit development [20].

We used the $2^{-\Delta \Delta C t}$ method to calculate the expression level of SmMsrA in ovaries or fruits of P-10 and 03-2 during six fruit developmental stages under natural cold stress and normal temperature (Figure 5).

The expression level of SmMsrA in the stiff fruit of 03-2 formed under cold stress (Figure 5C) was obviously lower than that in the normally expanded fruits (Figure 5A, 5B, 5C) regardless of which gene was used as a reference gene.

In the normally expanded fruit (Figure 5A, 5B, 5C), using D5, APRT, D4, D5+APRT+D4 and Actin for normalization, the expression trend of SmMsrA was not the same. When using D5, APRT, and D4 D5+APRT+D4 as reference genes, the expression level of SmMsrA was lower and similar, decreasing after 10 DPA at 0, 2, 4, and 10 days post anthesis (DPA). Using Actin as a reference gene, the expression trend of SmMsrA was similar to that using D5, APRT, D4 or D5+APRT+D4 for normalization in the fruit of P-10 under cold stress; however, in the fruit at normal temperature, SmMsrA had the highest expression level on the anthesis day, while it was similar 
and higher at 2, 4 and 10 DPA. At 15 and 20 DPA, their expression levels continued to decline, and at 20 DPA, SmMsrA had the lowest expression level.

In some timepoints, especially in the early stage of fruit development (such as at 0, 2, and 4 DPA), SmMsrA had a higher expression level using Actin as the reference gene than using D5, APRT, and D4 D5+APRT+D4 as the reference genes.

We conclude that using different genes as reference genes may lead to results showing different expression levels and trends for the target genes. It is important to choose suitable genes as reference genes. Therefore, in our study, we chose the D5+APRT+D4 combination as a reference.

\section{Discussion}

qRT-PCR is a rapid, sensitive, specific and quantitative technique for gene expression analysis [21]. To compare gene expression abundance between different samples using qRT-PCR, selecting suitable reference genes for gene normalization is necessary [22]. Traditional reference genes were chosen based on their function, such as Actin and tubulin, which encode basic components of the cytoskeleton. Similarly, GAPDH, EF-1a and ubiquitin are involved in the basic metabolic processes of organisms. These traditional internal reference genes are assumed to be stably expressed across all materials and conditions. However, some research has shown that these traditional reference genes are not always stable across different experimental designs and plants [23-25]. Thus, it is imperative to identify new internal reference genes and select suitable reference genes for specific experimental conditions when studying gene expression patterns by qRT-PCR [26]. With the development of high-throughput sequencing technology, the selection range of housekeeping genes has been broadened by using transcriptome data to screen housekeeping genes. Based on transcriptome data collected before and after high-temperature stress in eggplant, two new reference genes (SmTRX and SmUCP) and one commonly used reference gene (SmEF1a) with stable expression were screened under $42^{\circ} \mathrm{C}$ high-temperature stress with different treatment times and in different tissues and species [13]. Zhou et al. selected 15 candidate reference genes from apple root RNA-Seq data to evaluate their potential use as reliable reference genes. Then, 5 stably expressed genes, namely, MDP0000095375, MDP0000147424, MDP0000233640, MDP0000326399 and MDP0000173025, were recommended for normalizing quantitative gene expression data in apple roots under various abiotic or biotic stresses [27]. In addition, transcriptome databases have been used to screen reliable reference genes in peony [28], lily [29] and cherry [30]. In our research, we selected eighteen candidate reference genes based on their low FPKM variance to investigate their suitability under cold stress and at normal temperatures during eggplant fruit development. The results showed that three genes, namely, D5, D4 and D1, were expressed stably during the development of eggplant fruits under low-temperature stress and at normal growth temperatures. Gene D5 is predicted to encode Elongation Factor $1 \mathrm{a}(E F 1 a)$, and D1 is predicted according to sequence similarity to encode ADP, an ATP carrier protein, which is involved in the basic metabolic processes of organisms. D4 is predicted to encode 40 S ribosomal protein S5, which encodes a basic component of the cell. Elongation factor $1 a$ and ribosomal protein are often used as reference genes, but they are not always suitable for different experimental conditions because many of these genes belong to gene families, and different members of the same gene family may have different expression patterns in the same samples. For example, in eggplant, the EF1a gene family has 11 members; one EF1a, which is expressed stably under high-temperature stress, is on scaffold Sme2.5_01406.1 [14], and the EF1a (D5) expressed stably under cold stress in our study is on scaffold Sme2.5_08608.1. Obviously, these two EF1a genes are different, and they are suitable for only specific conditions. Therefore, before a qRT-PCR experiment is conducted, selecting appropriate reference genes is necessary. Our results are useful for the analysis of gene expression in eggplant under low-temperature stress in the future. At the same time, these results also provide a reference for the discovery of new stably expressed internal reference genes.

Four reference gene selection tools, namely, geNorm, NormFinder, BestKeeper and RefFinder, were used in this study. GeNorm, NormFinder and BestKeeper are the most commonly used software to select reference genes. The results showed that the stability rankings of candidate reference genes varied across the three kinds of software (Table 2, Table 3), as reported in previous research $[13,31]$. Therefore, further comprehensive analysis should be conducted, and RefFinder is an ideal choice. As a web-based tool, RefFinder is very convenient for researchers screening for candidate reference genes synthetically. In addition, by integrating the results from geNorm, NormFinder and BestKeeper to compare and rank the tested reference genes based on the geometric mean of the weights of every individual gene calculated by each programme, RefFinder can help researchers identify the ideal reference genes [26]. In this study, the results from the geNorm software revealed that at least two reference genes were needed under cold stress conditions and across all samples, and at least three reference genes were needed at normal temperature. Taking into account our practical experimental conditions, we recommend using three reference genes when analysing gene expression in this study. As the

Page 5/29 
primary result from RefFinder, D5, D4 and D1 always ranked in the top three (Table 3). However, when comparing the stability of these three genes with some commonly used reference genes, D4 and D1 were less stable than APRT, so D5, APRT, and D4 were the top three stable reference genes, while Actin was the least stable gene in the cold stress sample set and across all samples, as shown by the subsequent RefFinder results (Table 4). The stability comparison results confirmed that D5, D4 and APRT were more stable than $\mathrm{D} 1$ as reference genes. In the end, we decided on D5, APRT, and D4 as our final reference gene combination.

The availability of D5, APRT, and D4 was compared with Actin by analysing the expression levels of SmMsrA. Different expression trends were obtained using Actin as a reference gene compared with D5, APRT and D4 as reference genes. In addition, using the least stable reference gene, Actin, for normalization, the expression level was higher at some time points; for example, 4.24-fold, 5.14-fold, 7.12-fold, and 5.38-fold increases were found compared with normalization to D5, APRT, D4 and D5 + APRT+D4 as reference genes, respectively, on anthesis day in P-10 under cold stress (Fig. 5). These results indicated that the expression level of the target gene may be influenced by the stability of the internal controls. Therefore, it is necessary to select and evaluate suitable reference genes for specific qRT-PCR experiments .

Eggplant is a thermophilic crop that has a very high heat requirement [32]. Therefore, the yield of eggplant is influenced by cold stress. To overcome these disadvantages, growers generally heat greenhouses and treat flowers with plant hormones [33]. However, these methods not only are time consuming and laborious but also greatly increase the cost of cultivation. Therefore, the selection and cultivation of cold-resistant eggplant lines is highly important. Transcript analysis of cold-resistance-related genes in eggplant can provide insights into the molecular mechanism of cold resistance, thus promoting the breeding of cold-resistant eggplant varieties. We hope that this study will not only lay a foundation for subsequent gene expression pattern analyses of these differentially expressed genes but also provide more choices for reference genes in Solanaceae crops.

\section{Conclusions}

With the rapid development of high-throughput sequencing technology, using transcriptome data to screen housekeeping genes has broadened the selection range and quantity of reference genes. Our study first selected and evaluated 18 candidate reference genes of eggplant under cold stress. We selected three stable genes, D5 (Sme2.5_08608.1_g00002.1), D4 (Sme2.5_00276.1_g00016.1) and D1 (Sme2.5_01136.1_g00003.1), from fruit (ovary) transcriptome datasets. A further stability comparison was made between the three genes and the commonly used reference genes Actin, GAPDH, TUB, APRT and 18S ribosomal RNA (18S). As the results showed, D5 still had the best stability (except across all samples as calculated by BestKeeper), followed by APRT and D4. Actin showed the least stability among the sample sets of cold stress, normal temperature and all samples in P-10 and $03-2$, which indicated that commonly used reference genes may not be suitable for some specific experimental conditions. In addition, the expression level of SmMsrA normalized to D5, APRT, D4, D5 + APRT + D4 and the least stable commonly used reference gene, Actin, indeed showed some significant differences $(p<0.05)$, especially on biological samples from the day of anthesis and 2 days post anthesis.

Therefore, it is necessary for researchers to select suitable reference genes for gene normalization when using qRT-PCR. In the end, we recommended D5, APRT, and D4 as a reference combination by considering the comparison results and the previous selection work synthetically in this study.

\section{Methods}

\section{Plant materials and cultivation conditions}

The eggplant cold-resistant line P-10 and non-cold-resistant line $03-2$ were used as the plant materials in this study. P-10 was selected from round purple eggplant with cold resistance by self-cross selective breeding, which has facultative parthenocarpy in which parthenocarpic fruit is produced normally without pollination and fertilization at low temperatures (daily minimum temperature ranges from $7{ }^{\circ} \mathrm{C}$ to $15^{\circ} \mathrm{C}$ during the anthesis and fruiting periods) and seeded fruit is produced at normal temperatures. $03-2$ was selected from local round purple eggplant variety by self-cross selective breeding, which produces stiff fruit at low temperatures and seeded fruit at normal temperatures. These two materials were planted in Beijing (116 $\left.13^{\prime} \mathrm{E} ; 39^{\circ} 92^{\prime} \mathrm{N}\right)$ from February to June.

Seeds of the two lines were sown in plastic pots in a greenhouse and maintained at $15 \sim 30^{\circ} \mathrm{C}$ and $50 \%$ relative humidity under natural light conditions from February to April. In April, when the plants had approximately 8 leaves, they were transplanted into an open field. The samples were collected under two conditions: natural cold stress and normal temperature. From late April to early 
May, the natural daily minimum temperature in the open field was $7-17{ }^{\circ} \mathrm{C}$, which caused the eggplant to undergo cold stress during anthesis of the first fruit, and ovaries or fruit samples at $0,2,4,10,15$, and 20 days post anthesis (DPA) were collected. From June to early July, the natural daily minimum temperature was $17-28^{\circ} \mathrm{C}$, which was suitable for eggplant during anthesis of the fourth fruit, and then the ovaries or fruit samples at $0,2,4,10,15$, and 20 DPA were collected as experience samples under normal temperature. In the end, four ovaries were collected as a biological sample at 0,2 and 4 DPA, while four sarcocarps were collected as a biological sample at 10,15, and 20 DPA. Three biological replicates were performed for each time point, plant material, and temperature condition, and finally, a total of 72 biological samples were collected by Jinkun Yang. All sample collections were got permissions from our institution and complied with institutional guidelines, which were wrapped in tinfoil, frozen immediately in liquid nitrogen and stored at $-80^{\circ} \mathrm{C}$ in our laboratory for subsequent experiments.

\section{RNA isolation and first-strand cDNA synthesis}

Total RNA was extracted using a Quick RNA isolation kit (Huayueyang, Beijing, China) according to the manufacturer's instructions. The integrity of total RNA was detected by $1.0 \%$ agarose gel electrophoresis to ensure that no degradation occurred. In addition, RNA purity and concentration were determined using a BioSpec-nano Micro-volume UV spectrophotometer (BIOSPEC-NANO, Shimadzu, Japan). RNA samples with an OD260/OD280 value between 1.9 and 2.2 and an OD260/OD230 value greater than 2.0 were used for cDNA synthesis. First-strand cDNA synthesis was conducted using a $5 \times$ All-In-One Master Mix reverse transcription kit (Applied Biological Materials, Vancouver, Canada) according to the manufacturer's instructions. The cDNA solution was stored at $-20^{\circ} \mathrm{C}$.

\section{Source of candidate reference genes and primer design}

In total, 18 genes with an appropriate expression level and small coefficient of variation (CV) of FPKM values from eggplant transcriptome data (unpublished data) were selected as candidate reference genes. Primer pairs (Table 1) were designed using PrimerSelect, a tool in the DNASTAR Lasergene package (DNASTAR, Wisconsin, USA), with the following parameter settings: a melting temperature of greater than $55^{\circ} \mathrm{C}$, a primer length of $18-25 \mathrm{bp}$ and an amplicon length of $100-200 \mathrm{bp}$. The candidate reference gene sequences and primers can be found in the Eggplant Genome DataBase (http://eggplant.kazusa.or.jp/).

\section{Real-time quantitative PCR analysis}

qRT-PCR analysis was conducted in 384-well plates using a LightCycler 480 SYBR Green I Master kit and LightCycler 480 system (Roche, Germany) with the following reaction conditions: the total reaction volume was $10 \mu \mathrm{l}$ and contained $2 \mu \mathrm{l}(50 \mathrm{ng} / \mu \mathrm{l})$ of template, $0.5 \mu \mathrm{l}(10 \mu \mathrm{M})$ forward and reverse primers, $5 \mu$ l of SYBR Green I Master Mix and $2.5 \mu$ l of nuclease-free $\mathrm{H}_{2} \mathrm{O}$. In addition, the reaction programme included preincubation at $95^{\circ} \mathrm{C}$ for $10 \mathrm{~min}$, followed by 40 cycles of amplification at $95^{\circ} \mathrm{C}$ for $10 \mathrm{~s}, 56^{\circ} \mathrm{C}$ for $20 \mathrm{~s}$ and $72{ }^{\circ} \mathrm{C}$ for $30 \mathrm{~s}$ in single acquisition mode; melting at $95^{\circ} \mathrm{C}$ for $5 \mathrm{~s}, 65^{\circ} \mathrm{C}$ for 1 min and $97{ }^{\circ} \mathrm{C}$ in continuous acquisition mode; and, finally, cooling at $40^{\circ} \mathrm{C}$ for $10 \mathrm{~s}$. All reactions were conducted with three biological replicates and three technical replicates. The primer efficiency of each reference gene and the amplification specificity were analysed by a standard curve and a melting curve. To generate the standard curves, the cDNA solution was first diluted from that used for reverse transcription 10 times, followed by a fivefold or tenfold dilution series $(1 / 5,1 / 25,1 / 125$, and $1 / 625$ or $1 / 10,1 / 100,1 / 1000$, and $1 / 10000)$. After the qRT-PCR procedure was completed, the melting curves and the standard curves were analysed through $\mathrm{Tm}$ calling and advanced relative quantification analysis in the LightCycler 480.

\section{Candidate reference gene expression stability analysis}

The primer pair specificity of the 18 genes was confirmed according to the melting curve results. The amplification efficiency of these genes was obtained from the standard curve results. Boxplots of quantification cycle (Ct) values for the 18 candidate genes were drawn using SPSS Statistics version 17 software.

To evaluate the expression stability of the 18 candidate reference genes in different developmental stages and under different temperature conditions, three gene-screening tools (geNorm, NormFinder and BestKeeper) and one online tool (RefFinder, http://150.216.56.64/referencegene.php?type=reference) were used to analyse and rank the candidate reference genes. The methods and emphases of these tools differ; therefore, they might produce different results regarding the expression stability of the same gene [34]. As a visual basic application (VBA) for Microsoft Excel, geNorm relies on the principle that two ideal reference genes should be expressed identically in all samples regardless of the experimental conditions and tissue types. This tool can

Page $7 / 29$ 
automatically calculate the gene stability value $\mathrm{M}$ for all reference genes in all samples so that the best stable reference genes can be selected according to the value of $\mathrm{M}$. Furthermore, this application can determine the number of housekeeping genes that are necessary for accurate normalization through pairwise variation $(V n / n+1)$ [4]. Similar to geNorm, NormFinder is a VBA for Microsoft Excel that calculates the stability value for all candidate normalization genes automatically but provides the best stable gene [16]. BestKeeper, a tool that determines the best-suited standard from ten candidate genes and then combines them into an index, was established as an Excel-based spreadsheet software application for biological material tests [17]. Finally, RefFinder is a web-based, comprehensive tool that was developed to evaluate and screen reference genes from extensive experimental datasets to compare and rank candidate reference genes.

\section{Further stability comparison of the identified reference genes}

To confirm the stability of our selected reference genes and the necessity to screen reference genes, a further stability comparison between the identified reference genes and those commonly used reference genes, Actin, GAPDH, TUB [24], APRT and 18S ribosomal RNA (18S) [35], was made using the same tools.

\section{Validation of the final selected reference genes}

An eggplant peptide methionine sulfoxide reductase A gene, namely, STMSrA, was selected to validate the reliability of the identified reference genes. The gene expression abundance in eggplant ovaries or fruit during six fruit developmental stages under the conditions of natural cold stress and normal temperature were normalized using the most stable reference genes as well as the least stable reference gene from the stability comparison results. The relative expression of SmMsrA was calculated using the $2^{\wedge-\Delta \Delta C t}$ method.

\section{Abbreviations}

cDNA: coding Deoxyribo Nucleic Acid; FPKM: Fragments Per Kilobase of exon model per Million mapped fragments

\section{Declarations}

\section{Ethics approval and consent to participate}

Not applicable.

\section{Consent to publish}

All the authors consent to publish.

\section{Availability of data and materials}

The datasets and materials used and analyzed during the current study are available from the corresponding author upon reasonable request.

\section{Competing interests}

The authors declare that they have no competing interests.

\section{Funding}

The research was mainly funded by the National Natural Science Foundation of China (31572122), which provided the basic research funding. It also founded by the Science and Technology Innovation Project of the Chinese Academy of Agricultural Sciences (CAAS-ASTIP-IVFCAAS) and Fundamental Research Funds for Central Non-profit Scientific Institution (IVF-BRF2018008), whcih provided the plant materials breeding foundings and qRT-PCR experiment foundings.

\section{Author's Contributions}


FZL contributed to the conception of the study, prepared the plant materials and assisted in the qRT-PCR studies and data processing. JKY collected the plant samples, performed the RNA samples perparation, contributed to the experiment and data processing, and wrote the first draft of the manuscript. YL help to draft the manuscript, interpretation and helped to perform the qRTPCR experiment. YHC helped to analyze the final dataset, contributed to the study conception and helped to draft the manuscript. YZ helped to perform the qRT-PCR experiment, edited the manuscript and critical manuscript review. All authors read and approved the final manuscript.

\section{Acknowledgements}

Not applicable.

\section{References}

1. Nothmann, J.; Koller, D. Effects of growth regulators on fruit and seed development in eggplant (Solanum melongena L.). Horticult. Sci. Biotechnol. 1975, 50, 23-7.

2. Higuchi, R.; Fockler, C.; Dollinger, G.; Watson, R. Kinetic PCR analysis: real-time monitoring of DNA amplification reactions. BioTechnology. 1993, 11, 1026-30.

3. Schena, M.; Shalon, D.; Davis, R. W.; Brown, P. O. Quantitative monitoring of gene expression patterns with a complementary DNA microarray. Science. 1995, 270, 467-70.

4. Vandesompele, ; De Preter, K.; Pattyn, F.; Poppe, B.; Van Roy, N.; De Paepe, A.; Speleman, F. Accurate normalization of real-time quantitative RT-PCR data by geometric averaging of multiple internal control genes. Genome Biol, 2002, 3, research0034.1.

5. Wong, M. L.; Medrano, J. F. Real-time PCR for mRNA quantitation. BioTechniques. 2005, 39, 75-85.

6. Bustin, S. A. Quantification of mRNA using real-time reverse transcription PCR (RT-PCR): trends and problems. J Mol Endocrinol. $2002,29,23-39$.

7. Tong, Z.; Gao, Z.; Wang, F.; Zhou, J.; Zhang, Z. Selection of reliable reference genes for gene expression studies in peach using realtime PCR. BMC Mol Biol. 2009, 10, 71.

8. Li, J.; Han, J.; Hu, Y.; Yang, J. Selection of reference genes for quantitative real-time PCR during flower development in tree peony (Paeonia suffruticosa Andr.). Plant Sci. 2016, 7, 516.

9. Qi, S.; Yang, L. W.; Wen, X. H.; Hong, Y.; Song, X. B.; Zhang, M. M.; Dai, S. Reference gene selection for QRT-PCR analysis of flower development in chrysanthemum morifolium and chrysanthemum lavandulifolium. Front. Plant Sci. 2016, 7, 287.

10. Sinha, P.; Saxena, R. K.; Singh, V. K.; Krishnamurthy, L.; Varshney, R. K. Selection and validation of housekeeping genes as reference for gene expression studies in Pigeonpea (Cajanus cajan) under heat and salt stress conditions. Front. Plant Sci. 2015, 6, 1071.

11. Li, W.; Qian, Y. Q.; Han, L.; Liu, J. X.; Sun, Z. Y. Identification of suitable reference genes in buffalo grass for accurate transcript normalization under various abiotic stress conditions. Gene. 2014, 547, 55-62.

12. Zhou, X. H.; Liu, J.; Zhuang, Y. Selection of Appropriate Reference Genes in Solanum aculeatissimum for Quantitative Gene Expression Studies Under Different Experimental Conditions. Acta Hort Sin. 2014, 41, 1731-8.

13. Pang, Q. Q.; Li, Z. L.; Luo, S. B.; Jin, Q. M.; Li, Z. X.; Li, D. M.; Sun, B. J.; Sun, G. W. Selection and stability analysis of reference gene for qRT-PCR in eggplant Under high temperature stress. Acta Hort Sin. 2017, 44, 475-86.

14. Kanakachari, M.; Solanke, A. U.; Prabhakaran, N.; Ahmad, I.; Dhandapani, G.; Jayabalan, N.; Kumar, P. A. Evaluation of suitable reference genes for normalization of qPCR gene expression studies in brinjal (Solanum melongena $L$.) During fruit developmental stages. Biochem. Biotechnol. 2016, 178, 433-50. 
15. Xu, L. F.; Xu, H.; Cao, Y.; Yang, P.; Feng, Y.; Tang ,Y.; Yuan, S. Y.; Ming, J. Validation of reference genes for quantitative real-time PCR during bicolor tepal development in Asiatic hybrid lilies (Lilium spp.) Front. Plant Sci. 2017, 8, 669.

16. Wang, M.; Lu, S. Validation of Suitable Reference Genes for Quantitative Gene Expression Analysis inPanax ginseng. Front. Plant Sci. $2015,6,1259$.

17. Artico, S.; Nardeli, S. M.; Brilhante, O.; Grossi-de-Sa, M. F.; Alves-Ferreira, M. Identification and evaluation of new reference genes in Gossypium hirsutum for accurate normalization of real-time quantitative RT-PCR data. BMC Plant Biol. 2010, 10, 49.

18. Andersen, C. L.; Jensen, J. L.; Ørntoft, T. F. Normalization of real-time quantitative reverse transcription-PCR data: a model-based variance estimation approach to identify genes suited for normalization, applied to bladder and colon cancer data sets. Cancer Res. $2004,64,5245-50$.

19. Pfaffl, M. W.; Tichopad, A.; Prgomet, C.; Neuvians, T. P. Determination of stable housekeeping genes, differentially regulated target genes and sample integrity: BestKeeper - excel-based tool using pair-wise correlations. Biotechnol Lett. 2004, 26, 509-15.

Zhang, Z.; Liu, F. Z.; Zhang Y.; Qi D.X.; Chen, Y. H.; Lian, Y.; VIGS expression vector construction and expression analyses of SmMsrA gene in eggplant. Acta Hort Sin, 2015, 42, 1495-1504.

21. Udvardi, M. K.; Czechowski, T.; Scheible, W-R. Eleven golden rules of quantitative RT-PCR. Plant Cell. 2008, 20, $1736-7$.

22. Hu, R.; Fan, C.; Li, H.; Zhang, Q.; Fu, Y. F. Evaluation of putative reference genes for gene expression normalization in soybean by quantitative real-time RT-PCR. BMC Mol Biol. 2009, 10, 93.

23. Løvdal, T.; Lillo, C. Reference gene selection for quantitative real-time PCR normalization in tomato subjected to nitrogen, cold, and light stress. Anal Biochem. 2009, 387, 238-42.

24. Zhou, ; Liu, J.; Zhuang, Y. Selection of appropriate reference genes in eggplant for quantitative gene expression studies under different experimental conditions. Sci. Hortic. 2014, 176, 200-7.

25. Dheda, K.; Huggett, J. F.; Bustin, S. A.; Johnson, M. A.; Rook, G.; Zumla, A. Validation of housekeeping genes for normalizing RNA expression in real-time PCR. Biotechniques. 2004, 37, 112-4, 116, 118.

26. Galli, V.; Borowski, J. M.; Perin, E. C.; Messias, R. D.; Labonde, J.; Pereira I. D.; Silva, S. D. D.; Rombaldi, C. V. Validation of reference genes for accurate normalization of gene expression for real time-quantitative PCR in strawberry fruits using different cultivars and osmotic stresses. Gene. 2015, 554, 205-14.

27. Zhao, X.; Fu, J.; Jiang, L.; Zhang, W.; Shao, Y.; Jin, C.; Xiong, J. B.; Li, C. H. Transcriptome-based identification of the optimal reference genes as internal controls for quantitative RT-PCR in razor clam (Sinonovacula Constricta). Genes Genom.. 2018, 40, 60313.

28. Liu, H.; Gao, L.; Hu, Y. Reference genes discovery and selection for quantitative real-time PCR in tree peony seed and petal tissue of different development stages. J Agric Biotechnol. 2015, 23, 1639-48.

29. Li, X. Characterization of genes encoding SuSy and INV key enzymes for starch-sucrose metabolism in Lilium davidii var. unicolor using RNA-seq. [Ph. D. Dissertation]. Shengyang®Shengyang Agricultural University; 2015. Available from: CNKI (http://www.cnki.net/).

30. Zhu, Y.; Wang, Y.; Zhang, H. Selection and characterization of reliable reference genes in Chinese cherry (Prunus pseudocerasus) using quantitative real-time PCR (qRT-PCR). J Agric Biotechnol. 2015, 23, 690-700.

31. Tang, X.; Zhang, N.; Si, H.; Calderón-Urrea, A. Selection and validation of reference genes for qRT-PCR analysis in potato under abiotic stress. Plant Methods. 2017, 13, 85.

32. Donzella, G.; Spena, A.; Rotino, G. L. Transgenic parthenocarpic eggplants: superior germplasm for increased winter production. Mol Breed. 2000, 6, 79-86. 
33. Liu, F.; Lian, Y.; Chen, Y. The effect of temperature and bud stage treatment on parthenocarpic gene expression of eggplant. Acta Hort Sin. 2005.

34. Yim, A. K.; Wong, J. W.; Ku, Y. S.; Qin, H.; Chan, T. F.; Lam, H. M. Using RNA-Seq data to evaluate reference genes suitable for gene expression studies in soybean. PLoS One. 2015, 10, e0136343: e136343.

35. Wan, F.; Pan, Y.; Li, J.; Chen, X.; Pan, Y.; Wang, Y.; Tian, S.; Zhang, X. Heterologous expression of Arabidopsis C-repeat binding factor 3 (AtCBF3) and cold-regulated 15A (AtCOR15A) enhanced chilling tolerance in transgenic eggplant (Solanum melongena L.). Plant Cell Rep. 2014, 33, 1951-1961.

\section{Supplementary Information}

Additional file 1. Supplementary Table S1: Ct values of 18 candidate reference genes on 72 biological samples.

Additional file 2. Supplementary Table S2: Ct values of D1, D4, D5 and five commonly used reference genes.

Additional file 3. Supplementary Table S3: Relative expression of SmMsrA normalized by D5, APRT, D4, D5+APRT+D4 and Actin.

Additional file 4. The original image of gels (modified by photoshop)(Please note: The original picture of Figure 5 was lost, we performed the agarose gel electrophoresis experiment with same conditions and got the same result, whcih confirmed our experiment is repeatable.).

\section{Tables}

Table 1 Information on candidate genes and primer sequences. 


\begin{tabular}{|c|c|c|c|c|c|}
\hline Code & Gene ID & Primer sequence (5'-3') & Length (bp) & $E(\%)$ & $\mathrm{R}^{2}$ \\
\hline D1 & Sme2.5_01136.1_g00003.1 & GGTGCTGCTGGTGCTTCCTCTTT & 107 & 96.20 & 0.9994 \\
\hline \multicolumn{6}{|c|}{ ААСТGССТСТСАССТСССТTСТTT } \\
\hline D2 & Sme2.5_06157.1_g00003.1 & AGTATGGCTTGACCCTAATGAA & 128 & 94.75 & 0.9670 \\
\hline \multicolumn{6}{|c|}{ GGGCGCGAGATCGTGAATGAAT } \\
\hline D3 & Sme2.5_04412.1_g00001.1 & TCCTGATTATTGACTCCACTACT & 184 & 81.05 & 0.9980 \\
\hline \multicolumn{6}{|c|}{ АСТТССТТСАСААТТТСАТСАТАС } \\
\hline D4 & Sme2.5_00276.1_g00016.1 & CCAGGCCAAGCGTTTCAGGA & 200 & 96.40 & 0.9977 \\
\hline \multicolumn{6}{|c|}{ СCCTTGGCCCACTGTTGATAAC } \\
\hline D5 & Sme2.5_08608.1_g00002.1 & GGGTAAAGAGAAGACTCACATCAG & 175 & 98.50 & 0.9979 \\
\hline \multicolumn{6}{|c|}{ CACCCAGGCATACTTGAATGAC } \\
\hline D6 & Sme2.5_10667.1_g00002.1 & GCTGCTCGTGTCCCCAAGAAGGT & 153 & 89.35 & 0.9998 \\
\hline \multicolumn{6}{|c|}{ CCATAAGTCGGGGGTCAGGAAC } \\
\hline D7 & Sme2.5_00488.1_g00017.1 & TTCATGACCAACAGGCTACTTTC & 134 & 97.55 & 0.9994 \\
\hline \multicolumn{6}{|c|}{ ATGGCATTTGGATCTTTCACTTC } \\
\hline D8 & Sme2.5_00499.1_g00025.1 & CGGAGCTGATTCGTGGAGTGG & 169 & 92.10 & 0.9931 \\
\hline \multicolumn{6}{|c|}{ ACGTCATCGGCGGGGTAGAAC } \\
\hline D9 & Sme2.5_01918.1_g00003.1 & CCACCGGTCAGCCAAGGAAGAG & 119 & 86.70 & 0.9995 \\
\hline \multicolumn{6}{|c|}{ GCGAGGACGAGCAGGGAAAAG } \\
\hline D10 & Sme2.5_00036.1_g00030.1 & GGAACCGGCGAGAAATGTG & 155 & 99.55 & 0.9951 \\
\hline \multicolumn{6}{|c|}{ CAATCAGGGTCGTATGGGGC } \\
\hline D11 & Sme2.5_00563.1_g00006.1 & GGAAACGGTACCGGAGGAGAAT & 146 & 99.90 & 0.9981 \\
\hline \multicolumn{6}{|c|}{ TTAGCGGTGCAGATGAAGAACT } \\
\hline D12 & Sme2.5_00417.1_g00023.1 & AGAAGGCAAAGATGGCTCGTGA & 133 & 98.00 & 0.9997 \\
\hline \multicolumn{6}{|c|}{ GAAGTGGTGCAAATGAATGTCTG } \\
\hline D13 & Sme2.5_00183.1_g00004.1 & GCGGGGAATCTATTTACGGTGAG & 198 & 98.30 & 0.9998 \\
\hline \multicolumn{6}{|c|}{ AAACGACATCCATTCCAGACAAC } \\
\hline D14 & Sme2.5_00584.1_g00008.1 & TCGTCCACGTCATTTCTGTAAG & 178 & 95.25 & 0.9964 \\
\hline \multicolumn{6}{|c|}{ TCTCTGGCCGTTGGATGTGAT } \\
\hline D15 & Sme2.5_00079.1_g00001.1 & AGCCGCCACTTTCTCTGTCG & 161 & 96.90 & 0.9982 \\
\hline \multicolumn{6}{|c|}{ AATCCTCGCCCTGGCTGTCTTT } \\
\hline D16 & Sme2.5_06588.1_g00003.1 & TTCCAATCAACGCCTCCATCAC & 136 & 95.50 & 0.9985 \\
\hline \multicolumn{6}{|c|}{ AGCTCGTCCTTAACCTTTTCAGA } \\
\hline D17 & Sme2.5_06715.1_g00005.1 & CTGAGGCCTACTTGGTTGGTCTGT & 121 & 96.60 & 0.9900 \\
\hline \multicolumn{6}{|c|}{ TAAGCACGCTCGCCCCTAATAC } \\
\hline D18 & Sme2.5_00276.1_g00008.1 & ACGTCTTGTTCAGTCTCCTAAT & 168 & 89.40 & 0.9780 \\
\hline & & GAACATCCCTCGGTAAGTCT & & & \\
\hline
\end{tabular}


E represents the amplification efficiency. $R^{2}$ represents the correlation coefficient of the standard curve.

Table 2 Average expression stability values and rankings of candidate reference genes.

\begin{tabular}{|lllllll|}
\hline Ranking & Cold stress & $\boldsymbol{M}$ & Normal temperature & $\boldsymbol{M}$ & All samples & $\boldsymbol{M}$ \\
\hline 1 & D1/D2 & 0.39 & D4/D5 & 0.41 & D1/D2 & 0.46 \\
\hline 2 & D5 & 0.45 & D1 & 0.47 & D5 & 0.48 \\
\hline 3 & D3 & 0.54 & D2 & 0.50 & D3 & 0.55 \\
\hline 4 & D4 & 0.60 & D3 & 0.54 & D4 & 0.58 \\
\hline 5 & D13 & 0.66 & D8 & 0.62 & D12 & 0.65 \\
\hline 6 & D10 & 0.72 & D9 & 0.67 & D13 & 0.71 \\
\hline 7 & D6 & 0.75 & D7 & 0.70 & D7 & 0.75 \\
\hline 8 & D7 & 0.77 & D10 & 0.72 & D10 & 0.77 \\
\hline 9 & D12 & 0.78 & D15 & 0.73 & D6 & 0.79 \\
\hline 10 & D15 & 0.81 & D12 & 0.76 & D15 & 0.80 \\
\hline 11 & D9 & 0.85 & D13 & 0.77 & D9 & 0.82 \\
\hline 12 & D8 & 0.87 & D6 & 0.79 & D8 & 0.84 \\
\hline 13 & D16 & 0.90 & D17 & 0.81 & D16 & 0.87 \\
\hline 14 & D11 & 0.93 & D16 & 0.83 & D17 & 0.90 \\
\hline 15 & D14 & 0.96 & D11 & 0.85 & D11 & 0.92 \\
\hline 16 & D17 & 0.99 & D14 & 0.89 & D14 & 0.95 \\
\hline 17 & D18 & 1.10 & D18 & 0.96 & D18 & 1.04 \\
\hline
\end{tabular}

Table 3 Relevant stability evaluation values calculated by NormFinder, BestKeeper and RefFinder. 


\begin{tabular}{|c|c|c|c|c|c|c|c|c|}
\hline Cold stress & & & Normal & & & All samples & & \\
\hline NormFinder & BestKeeper & RefFinder & NormFinder & BestKeeper & RefFinder & NormFinder & BestKeeper & RefFinder \\
\hline Gene $M_{1}$ & Gene SD & Gene $M_{2}$ & Gene $M_{1}$ & Gene SD & Gene $M_{2}$ & Gene $M_{1}$ & Gene SD & Gene $M_{2}$ \\
\hline D4 0.33 & D5 0.575 & D5 1.57 & D5 0.25 & D10 0.574 & D5 1.19 & D5 0.30 & D5 0.607 & D5 1.32 \\
\hline D5 0.34 & D1 0.600 & D4 2.59 & D4 $\quad 0.27$ & D5 0.585 & D4 2.21 & D4 0.30 & D1 0.631 & D1 2.28 \\
\hline D3 0.35 & D4 0.668 & D1 3.15 & D1 0.30 & D8 $\quad 0.621$ & D1 3.22 & D1 0.37 & D10 0.632 & D4 2.99 \\
\hline D13 0.37 & D12 0.672 & D2 3.34 & D2 $\quad 0.34$ & D1 0.640 & D2 4.23 & D3 0.37 & D4 0.693 & D2 3.34 \\
\hline D2 0.40 & D2 0.677 & D3 3.94 & D9 $\quad 0.37$ & D2 0.669 & D10 5.48 & D2 0.39 & D2 0.708 & D10 5.24 \\
\hline D10 0.40 & D10 0.680 & D13 5.09 & D15 0.38 & D4 0.716 & D8 6.00 & D10 0.42 & D13 0.773 & D3 5.37 \\
\hline D1 0.42 & D13 0.726 & D10 6.24 & D3 0.39 & D17 0.730 & D9 6.47 & D7 0.43 & D17 0.773 & D7 7.80 \\
\hline D7 0.46 & D6 0.756 & D12 7.75 & D7 0.40 & D7 0.765 & D7 7.67 & D15 0.44 & D12 0.776 & D13 7.94 \\
\hline D12 0.46 & D17 0.809 & D6 8.92 & D8 $\quad 0.40$ & D6 $\quad 0.807$ & D3 7.91 & D12 0.46 & D6 0.783 & D12 8.32 \\
\hline D6 $\quad 0.50$ & D3 0.817 & D7 9.12 & D10 0.44 & D9 $\quad 0.819$ & D15 8.60 & D13 0.46 & D8 0.796 & D15 9.59 \\
\hline D15 0.50 & D15 0.835 & $\begin{array}{l}\text { D15 } \\
10.74\end{array}$ & D12 0.47 & D13 0.833 & $\begin{array}{l}\text { D17 } \\
10.90\end{array}$ & D8 0.49 & D7 0.822 & $\begin{array}{l}\text { D6 } \\
10.65\end{array}$ \\
\hline D16 0.54 & D7 0.874 & $\begin{array}{l}\text { D16 } \\
12.72\end{array}$ & D17 0.51 & D12 0.854 & $\begin{array}{l}\text { D12 } \\
11.24\end{array}$ & D9 $\quad 0.50$ & D15 0.881 & $\begin{array}{l}\text { D8 } \\
11.68\end{array}$ \\
\hline D8 0.56 & D16 0.926 & $\begin{array}{l}\text { D8 } \\
13.24\end{array}$ & D13 0.52 & D15 0.917 & $\begin{array}{l}\text { D13 } \\
12.22\end{array}$ & D6 $\quad 0.51$ & D3 0.895 & $\begin{array}{l}\text { D17 } \\
12.32\end{array}$ \\
\hline D9 0.60 & D8 0.971 & $\begin{array}{l}\text { D9 } \\
13.71\end{array}$ & D6 0.53 & D3 0.937 & $\begin{array}{l}\text { D6 } \\
12.31\end{array}$ & D16 0.55 & D9 0.907 & $\begin{array}{l}\text { D9 } \\
12.47\end{array}$ \\
\hline D11 0.61 & D9 0.979 & $\begin{array}{l}\text { D17 } \\
14.50\end{array}$ & D16 0.53 & D11 0.962 & $\begin{array}{l}\text { D16 } \\
15.24\end{array}$ & D11 0.61 & D16 0.99 & $\begin{array}{l}\text { D16 } \\
14.24\end{array}$ \\
\hline D14 0.68 & D14 1.047 & $\begin{array}{l}\text { D11 } \\
15.48\end{array}$ & D11 0.56 & D16 0.974 & $\begin{array}{l}\text { D11 } \\
15.74\end{array}$ & D17 0.63 & D11 1.069 & $\begin{array}{l}\text { D11 } \\
15.49\end{array}$ \\
\hline D17 0.73 & D11 1.089 & $\begin{array}{l}\text { D14 } \\
16.00\end{array}$ & D14 0.73 & D14 1.128 & $\begin{array}{l}\text { D14 } \\
17.24\end{array}$ & D14 0.70 & D14 1.097 & $\begin{array}{l}\text { D14 } \\
17.00\end{array}$ \\
\hline D18 1.27 & D18 1.622 & $\begin{array}{l}\text { D18 } \\
18.00\end{array}$ & D18 0.97 & D18 1.130 & $\begin{array}{l}\text { D18 } \\
18.00\end{array}$ & D18 1.13 & D18 1.367 & $\begin{array}{l}\text { D18 } \\
18.00\end{array}$ \\
\hline
\end{tabular}

Table 4 Stability comparison between D5, D4, D1 and five commonly used reference genes. 


\begin{tabular}{|c|c|c|c|c|c|c|}
\hline \multirow{3}{*}{$\begin{array}{l}\text { Tools/Rank } \\
\text { GeNorm } \\
1\end{array}$} & \multicolumn{6}{|l|}{ Treatments } \\
\hline & \multicolumn{2}{|l|}{ Cold stress } & \multicolumn{2}{|c|}{ Normal temperature } & \multicolumn{2}{|c|}{ All samples } \\
\hline & $\mathrm{D} 5 / A P R T$ & 0.51 & $\mathrm{D} 5 / A P R T$ & 0.387 & $\mathrm{D} 5 / A P R T$ & 0.45 \\
\hline 2 & D4 & 0.58 & GAPDH & 0.447 & D4 & 0.529 \\
\hline 3 & D1 & 0.631 & $T U B$ & 0.502 & D1 & 0.603 \\
\hline 4 & $18 S$ & 0.674 & D1 & 0.534 & GAPDH & 0.669 \\
\hline 5 & GAPDH & 0.743 & D4 & 0.585 & TUB & 0.728 \\
\hline 6 & $T U B$ & 0.816 & $18 S$ & 0.673 & $18 S$ & 0.774 \\
\hline 7 & Actin & 0.879 & Actin & 0.798 & Actin & 0.864 \\
\hline \multicolumn{7}{|l|}{ NormFinder } \\
\hline 1 & D5 & 0.302 & D5 & 0.089 & D5 & 0.214 \\
\hline 2 & $A P R T$ & 0.326 & GAPDH & 0.247 & $A P R T$ & 0.332 \\
\hline 3 & GAPDH & 0.537 & $A P R T$ & 0.347 & GAPDH & 0.514 \\
\hline 4 & D4 & 0.637 & $T U B$ & 0.372 & D4 & 0.591 \\
\hline 5 & D1 & 0.679 & D1 & 0.505 & D1 & 0.593 \\
\hline 6 & $18 S$ & 0.726 & D4 & 0.551 & $T U B$ & 0.628 \\
\hline 7 & $T U B$ & 0.774 & $18 S$ & 0.917 & $18 S$ & 0.831 \\
\hline 8 & Actin & 0.908 & Actin & 1.099 & Actin & 1.015 \\
\hline \multicolumn{7}{|l|}{ BestKeeper } \\
\hline D5 & & 0.57 & D5 & 0.59 & $18 S$ & 0.37 \\
\hline 2 & D4 & 0.57 & D4 & 0.56 & $A P R T$ & 0.48 \\
\hline 3 & D1 & 0.66 & D1 & 0.82 & D4 & 0.57 \\
\hline 4 & $18 S$ & 0.42 & $18 S$ & 0.3 & D5 & 0.58 \\
\hline 5 & $A P R T$ & 0.51 & $A P R T$ & 0.46 & D1 & 0.74 \\
\hline 6 & GAPDH & 0.89 & $G A P D H$ & 0.74 & $G A P D H$ & 0.86 \\
\hline 7 & $T U B$ & 1.04 & $T U B$ & 0.71 & $T U B$ & 0.87 \\
\hline 8 & Actin & 1.09 & Actin & 1.27 & Actin & 1.22 \\
\hline \multicolumn{7}{|l|}{ RefFinder } \\
\hline 1 & D5 & 1.41 & D5 & 1.41 & D5 & 1.41 \\
\hline 2 & $A P R T$ & 1.68 & $A P R T$ & 2.06 & $A P R T$ & 1.68 \\
\hline 3 & D4 & 3.46 & $G A P D H$ & 2.91 & D4 & 3.46 \\
\hline 4 & $18 S$ & 3.66 & $T U B$ & 4.23 & $G A P D H$ & 4.05 \\
\hline 5 & $G A P D H$ & 4.24 & $18 S$ & 4.3 & $18 S$ & 4.30 \\
\hline 6 & D1 & 4.73 & D4 & 5.05 & D1 & 4.73 \\
\hline 7 & $T U B$ & 7 & D1 & 5.44 & $T U B$ & 6.24 \\
\hline 8 & Actin & 8 & Actin & 8 & Actin & 8 \\
\hline
\end{tabular}




\section{Figures}

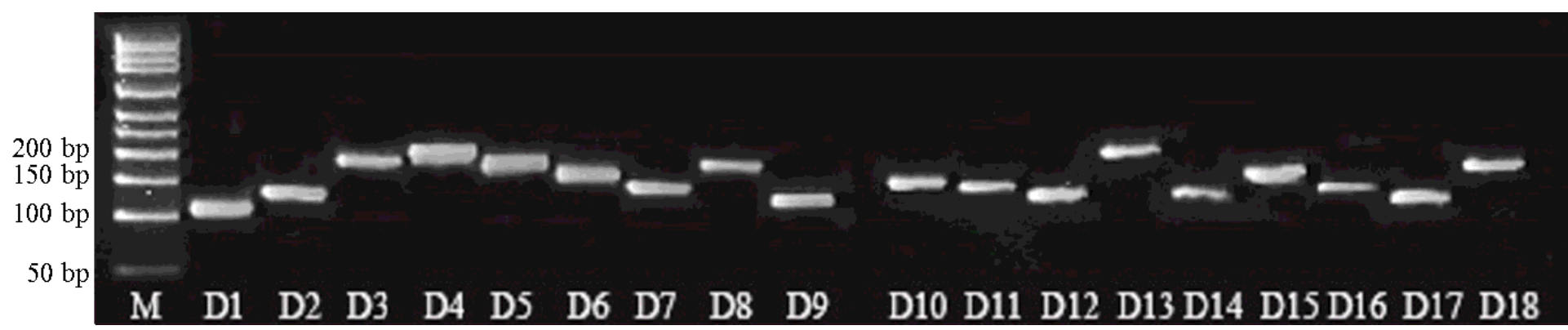

Figure 1

PCR products for 18 candidate reference genes. $M$ indicates a $50 \mathrm{bp}$ marker, and D1 to D18 represent the amplification products of the 18 candidate reference genes.

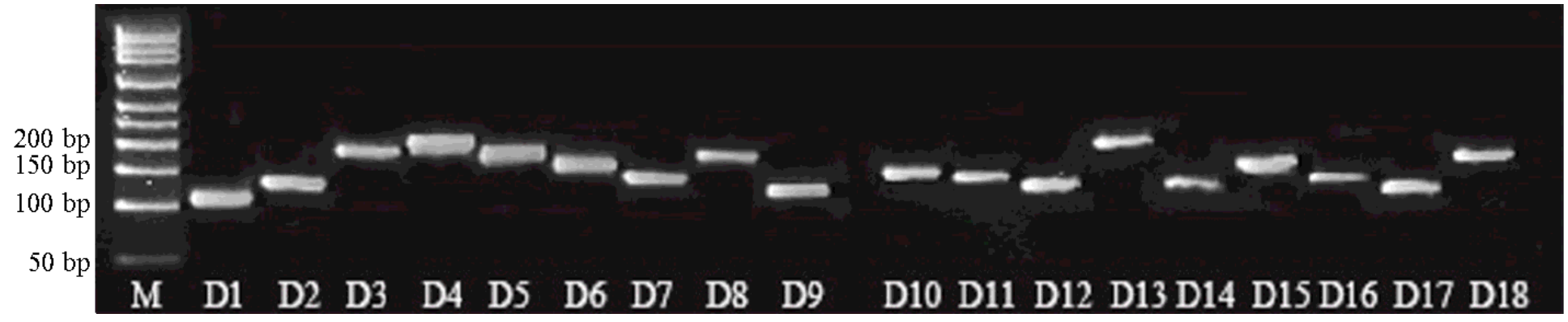

Figure 1

PCR products for 18 candidate reference genes. $M$ indicates a $50 \mathrm{bp}$ marker, and D1 to D18 represent the amplification products of the 18 candidate reference genes.

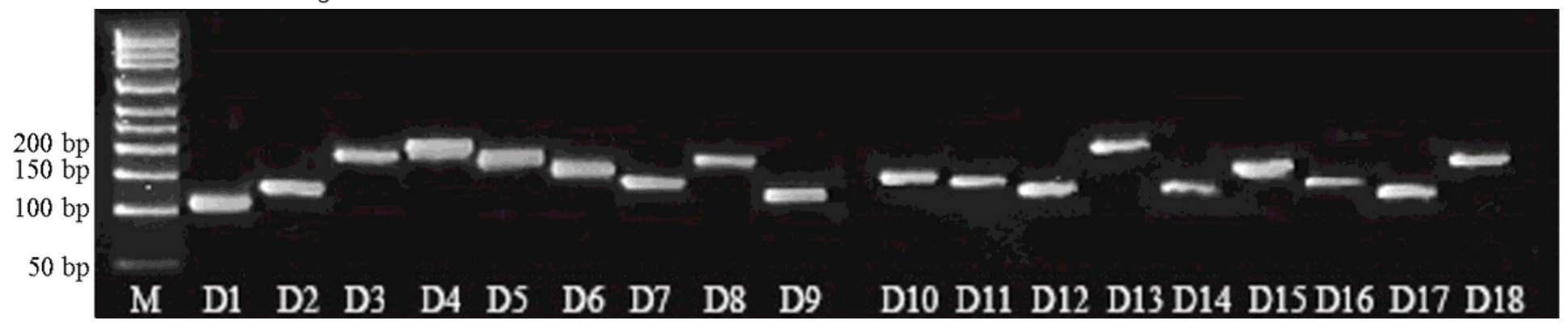

Figure 1

PCR products for 18 candidate reference genes. M indicates a $50 \mathrm{bp}$ marker, and D1 to D18 represent the amplification products of the 18 candidate reference genes.

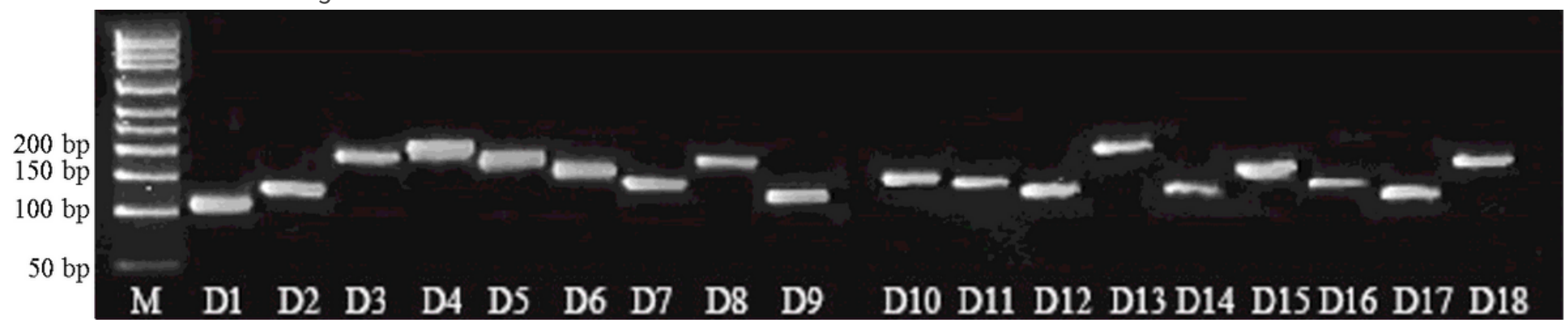

Figure 1 
PCR products for 18 candidate reference genes. M indicates a $50 \mathrm{bp}$ marker, and D1 to D18 represent the amplification products of the 18 candidate reference genes.

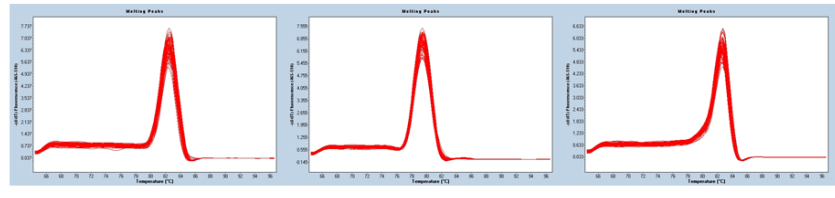

(D1) (D2) $\quad$ (D3)

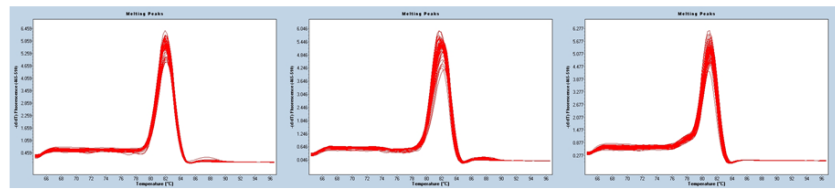

(D4)

(D5)

(D6)

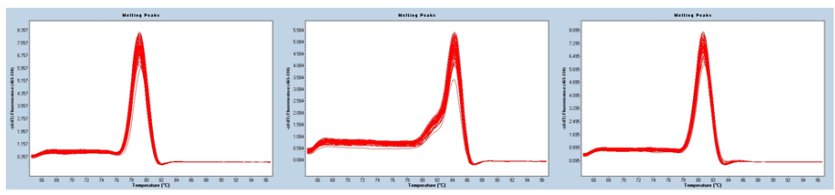

(D7)

(D8)

(D9)

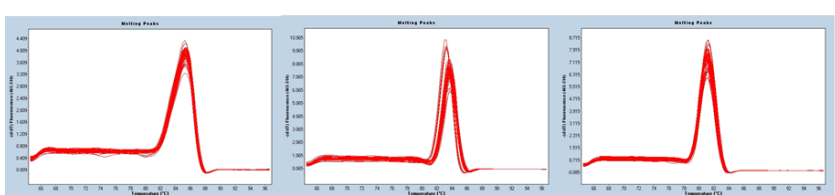

(D10)

(D11)

(D12)

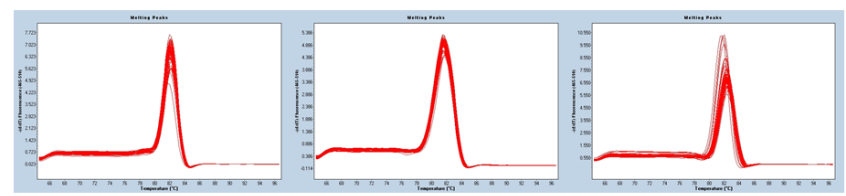

(D13)

(D14)

(D15)

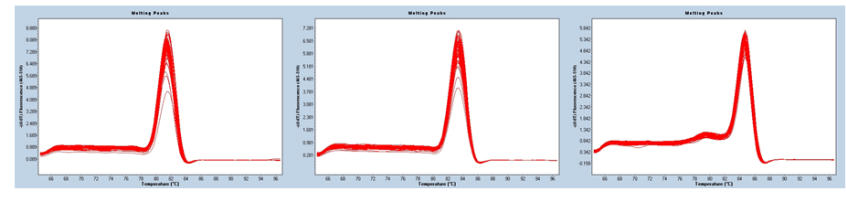

(D16)

(D17)

(D18)

\section{Figure 2}

Melting curves for 18 candidate reference genes. 


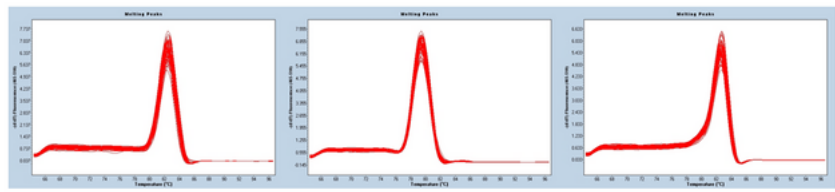

(D1)

(D2)

(D3)

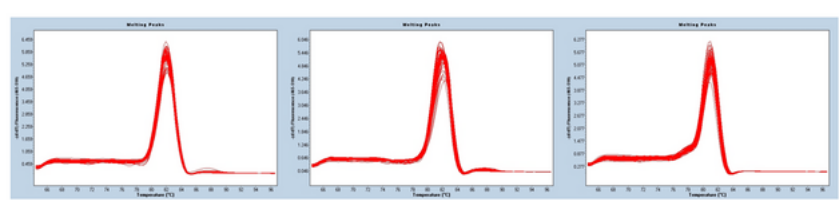

(D4)

(D5)

(D6)

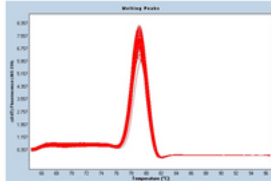

(D7)

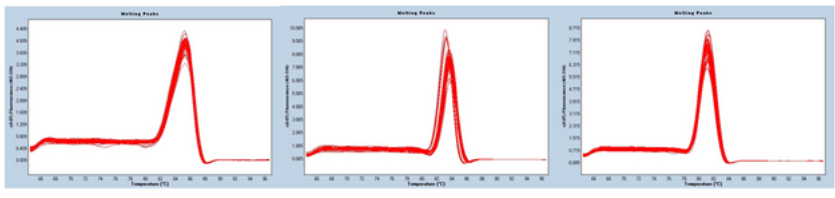

(D10)

(D11)

(D12)

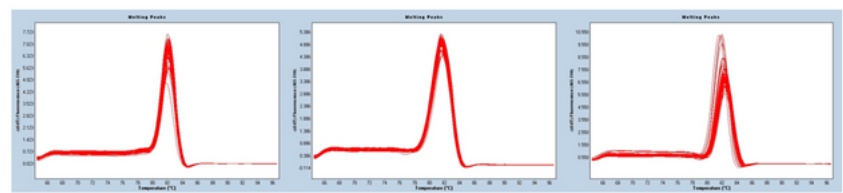

(D13)

(D14)

(D15)

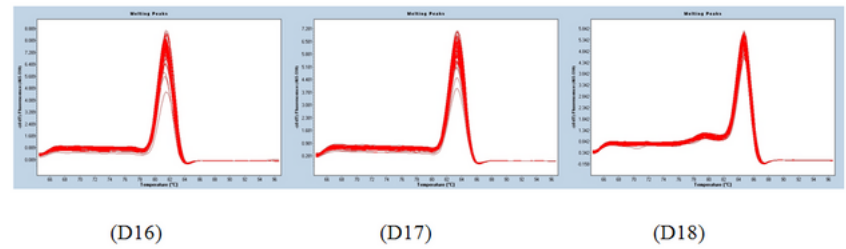

Figure 2

Melting curves for 18 candidate reference genes. 


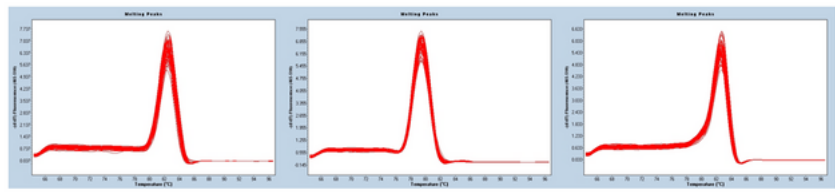

(D1)

(D2)

(D3)

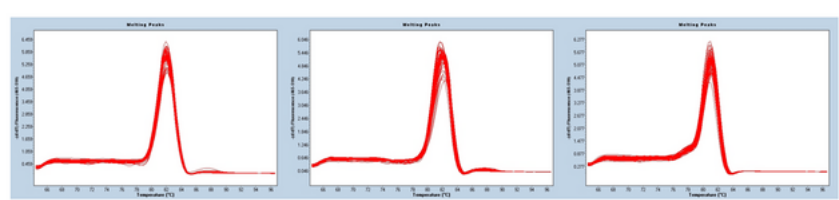

(D4)

(D5)

(D6)

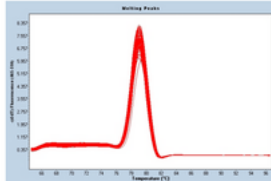

(D7)

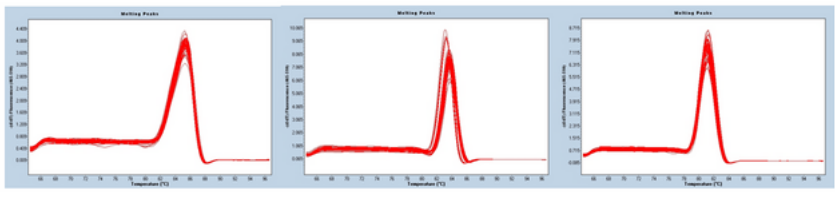

(D10)

(D11)

(D12)

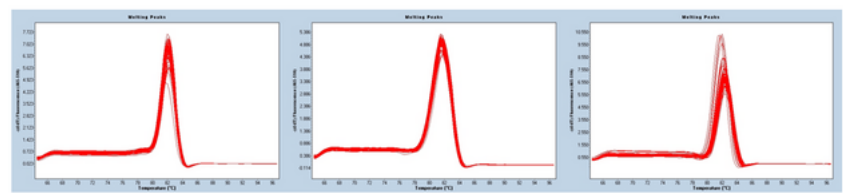

(D13)

(D14)

(D15)

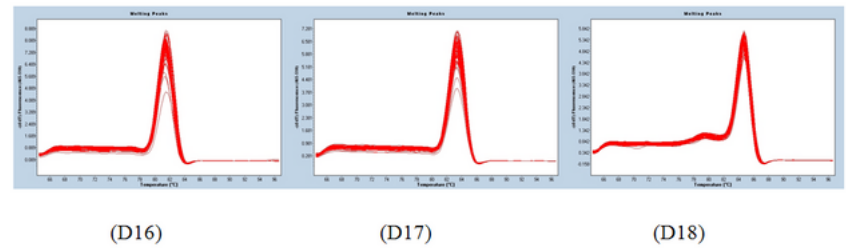

Figure 2

Melting curves for 18 candidate reference genes. 


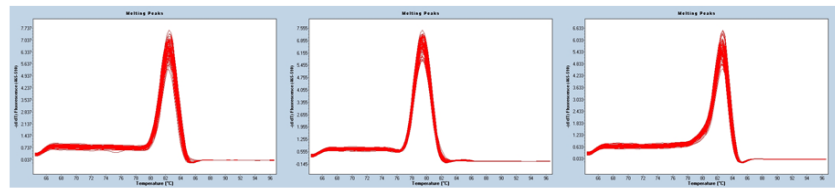

(D1)

(D2)

(D3)

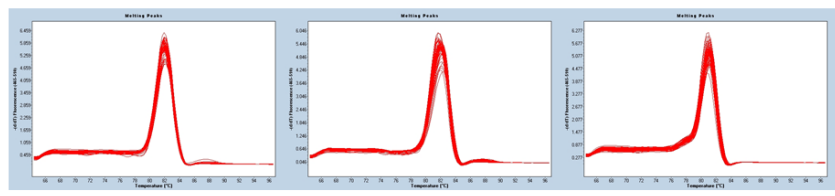

(D4)

(D5)

(D6)

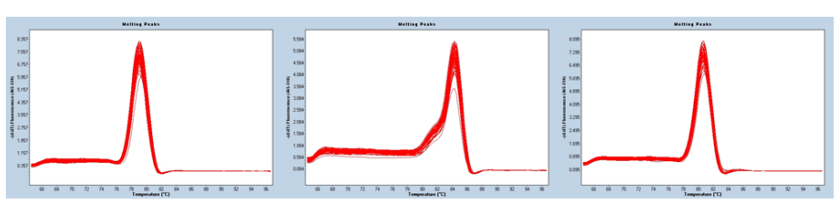

(D7)

(D8)

(D9)

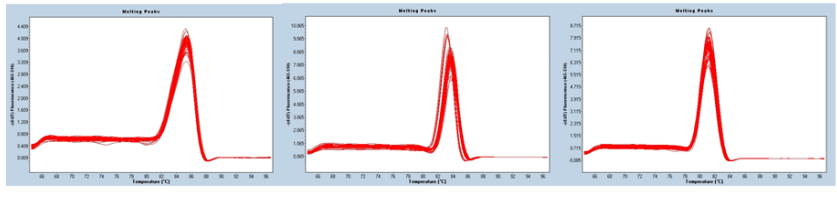

(D10)

(D11)

(D12)

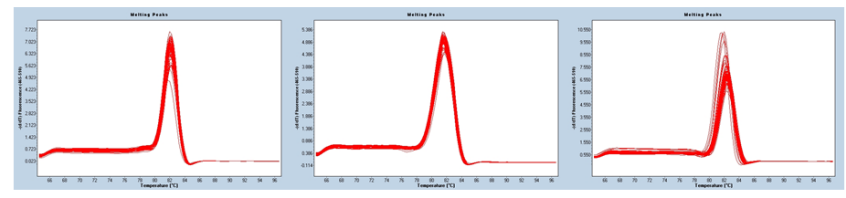

(D13)

(D14)

(D15)

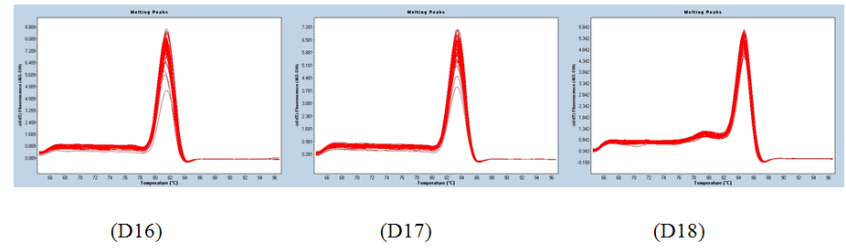

Figure 2

Melting curves for 18 candidate reference genes. 


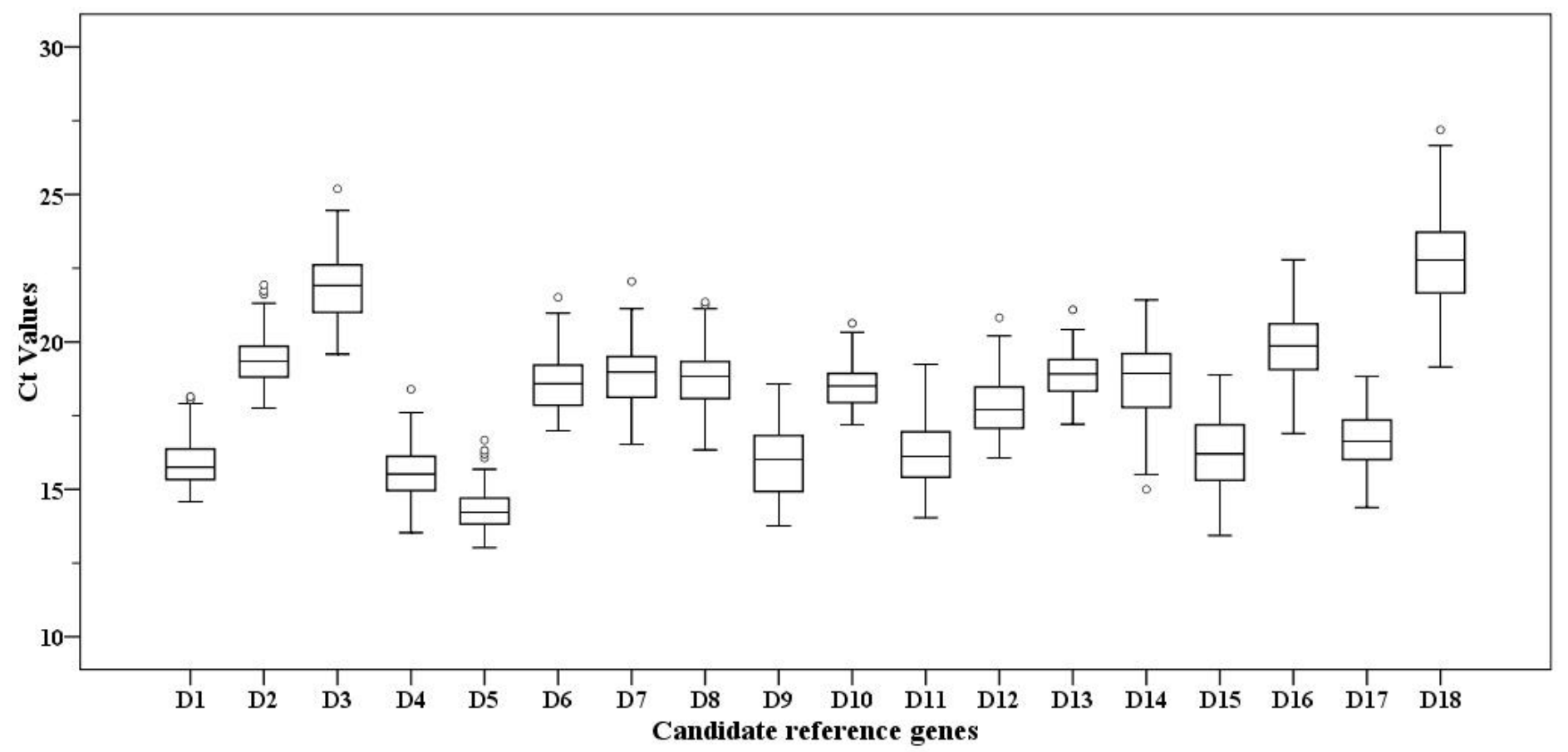

Figure 3

Expression levels of the 18 candidate reference genes in all samples. Variations are displayed as medians (lines), 25 to 75 th percentile ranges (boxes), and total ranges (whiskers).

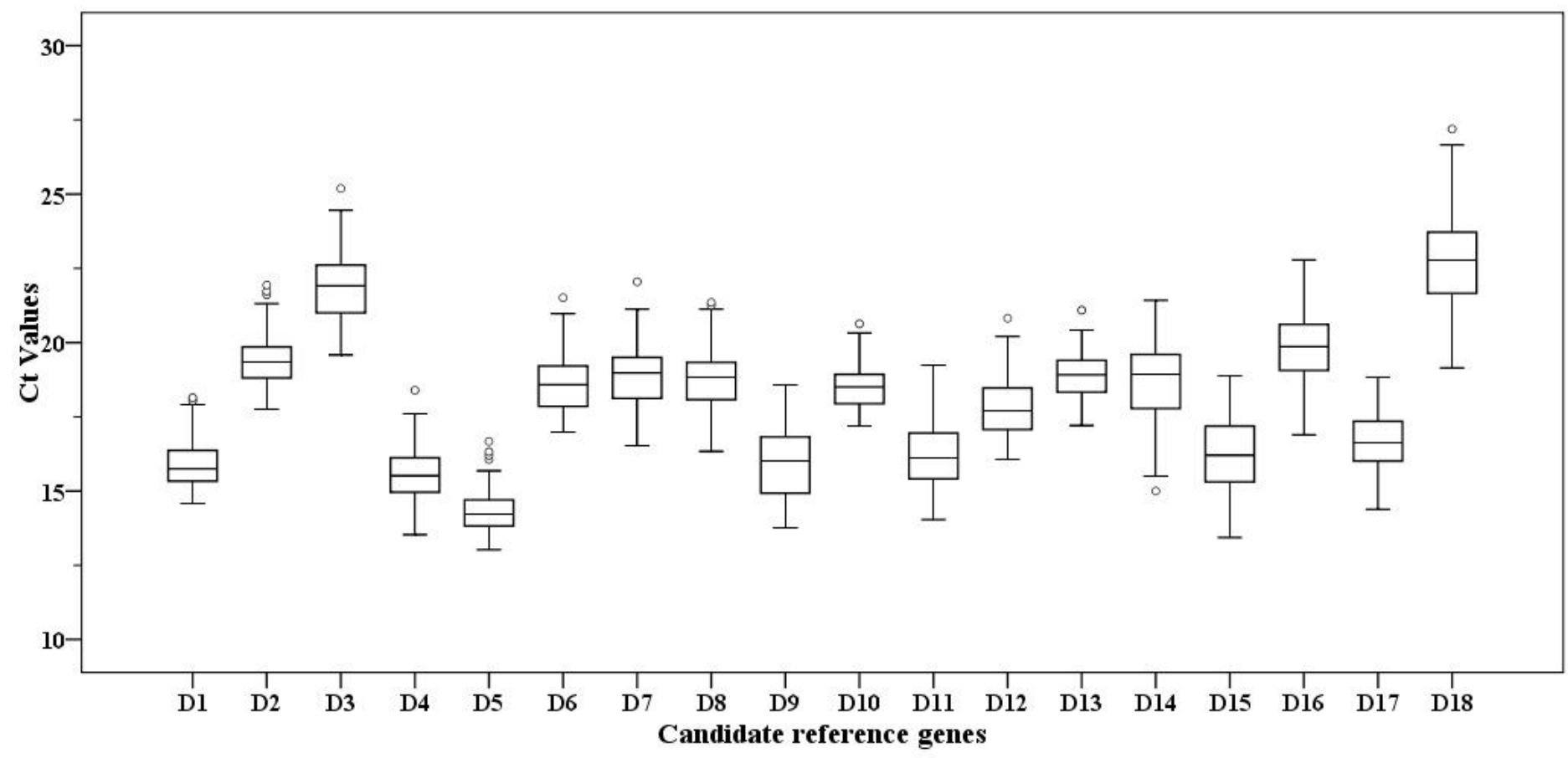

Figure 3

Expression levels of the 18 candidate reference genes in all samples. Variations are displayed as medians (lines), 25 to 75 th percentile ranges (boxes), and total ranges (whiskers). 


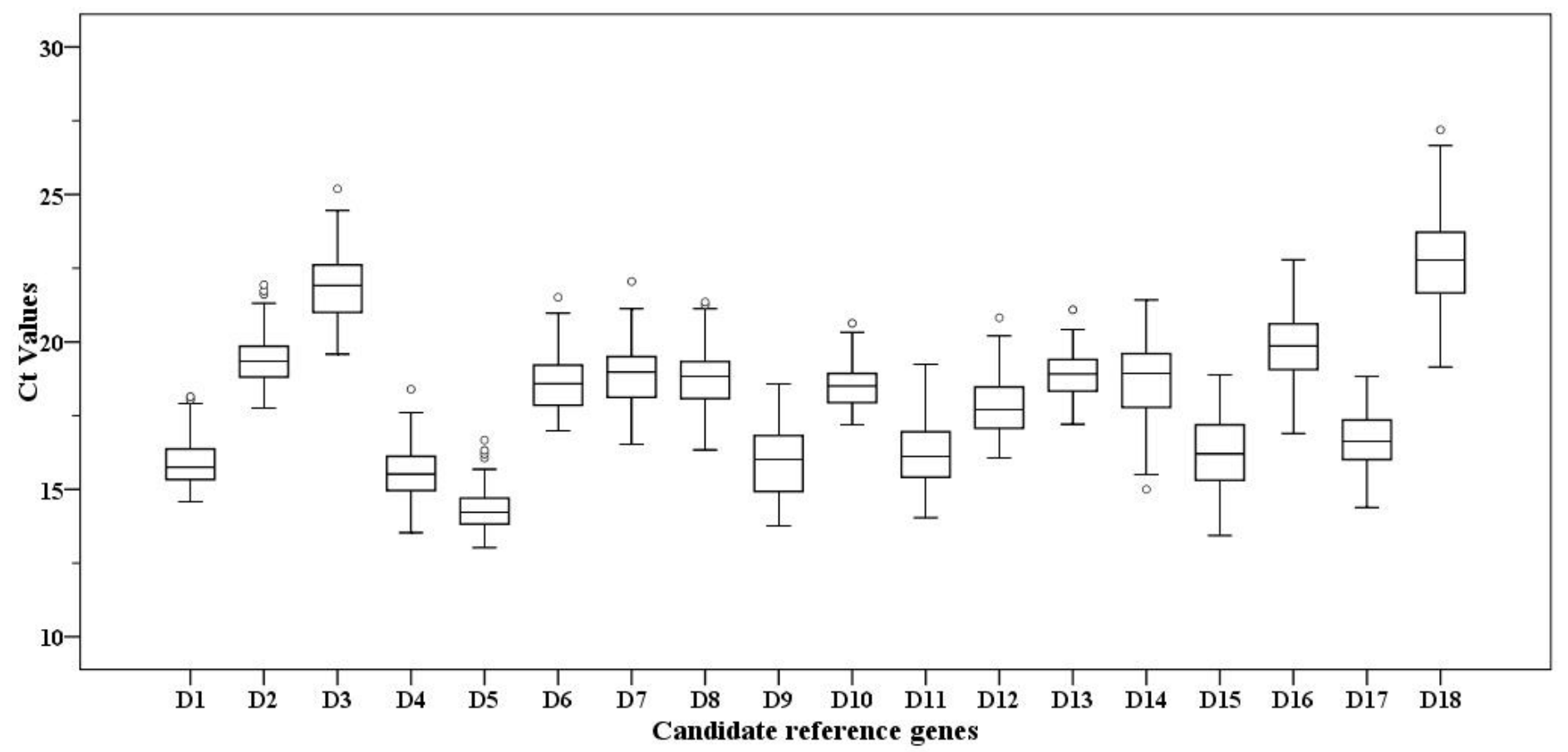

Figure 3

Expression levels of the 18 candidate reference genes in all samples. Variations are displayed as medians (lines), 25 to 75 th percentile ranges (boxes), and total ranges (whiskers).

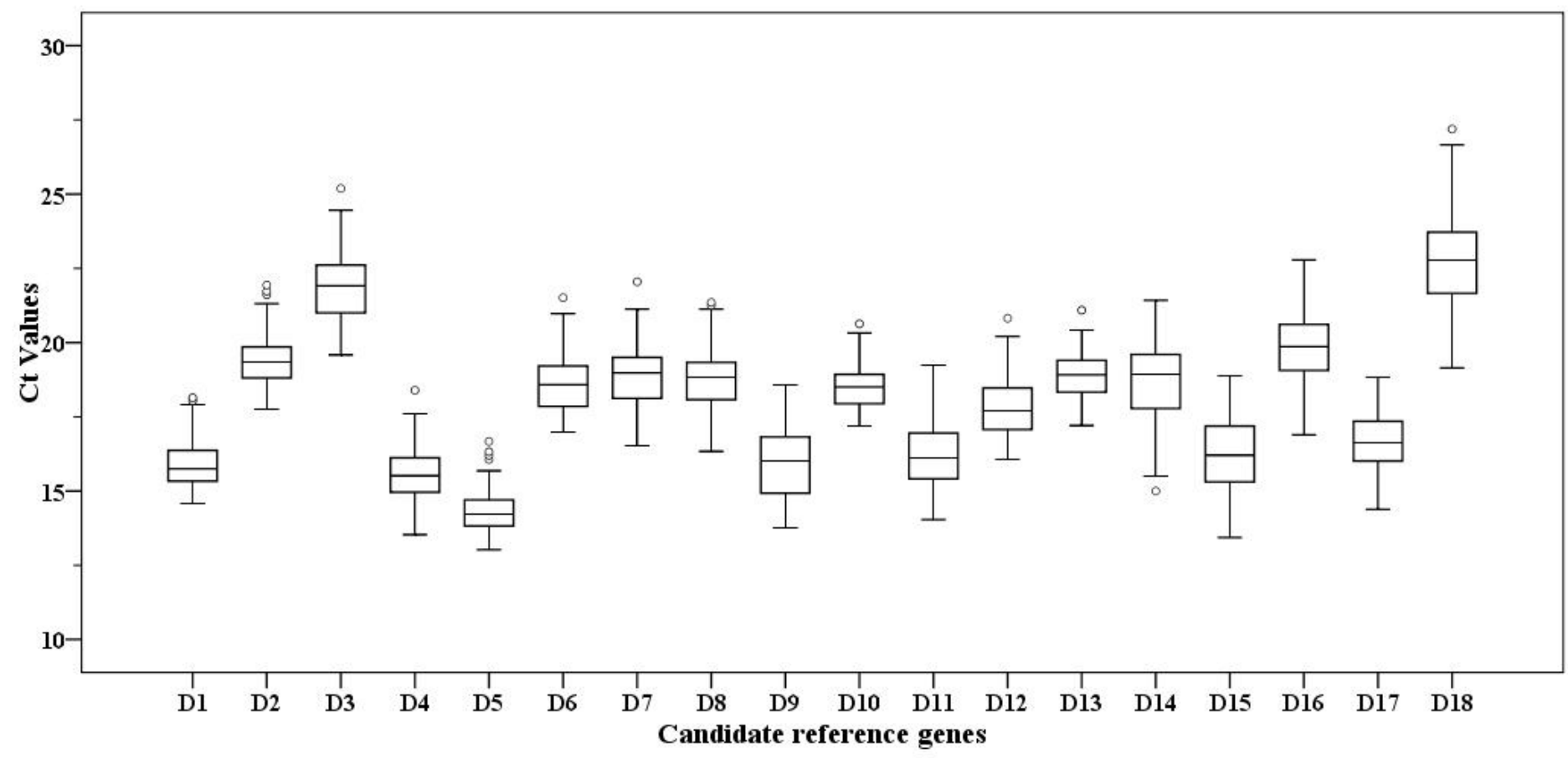

Figure 3

Expression levels of the 18 candidate reference genes in all samples. Variations are displayed as medians (lines), 25 to 75 th percentile ranges (boxes), and total ranges (whiskers). 


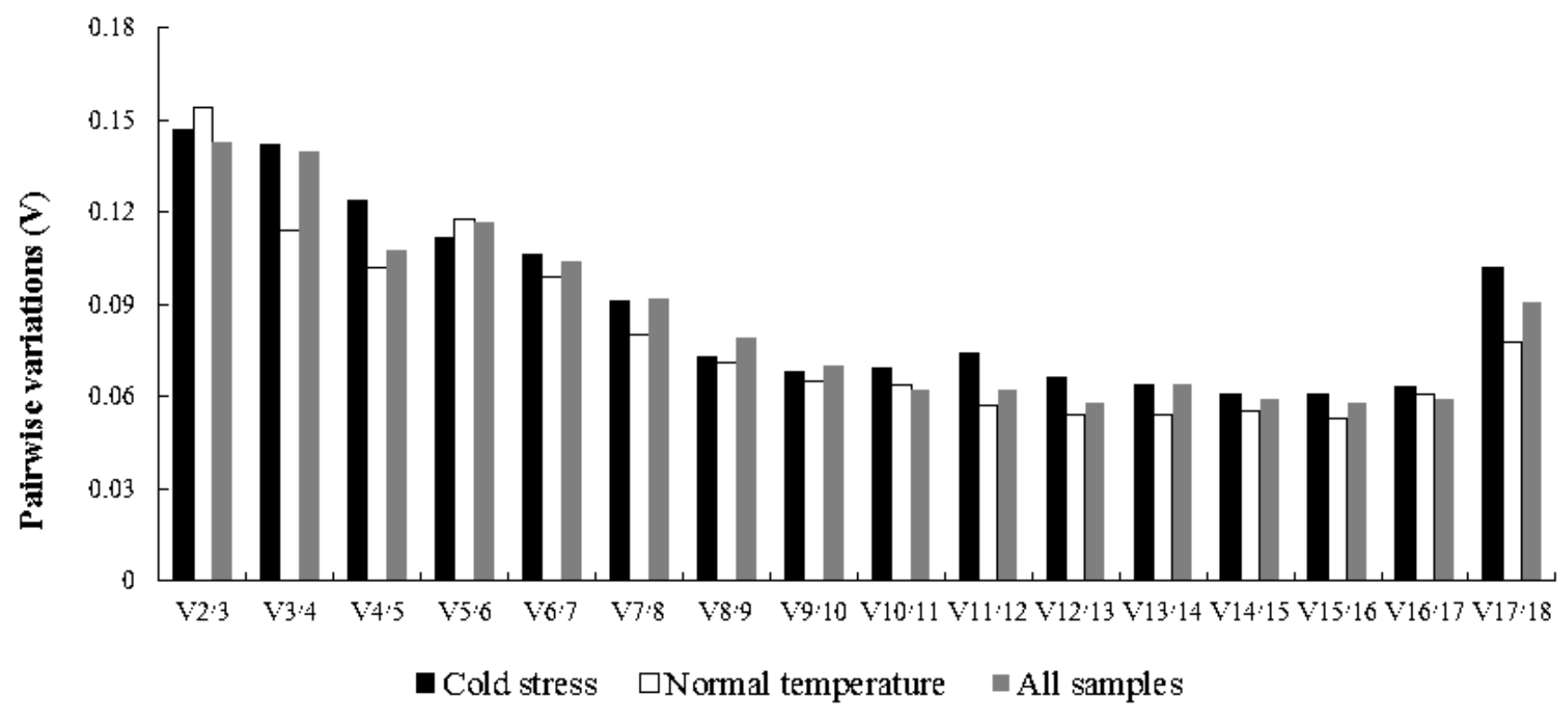

Figure 4

Pairwise variations of 18 candidate reference genes calculated by geNorm.

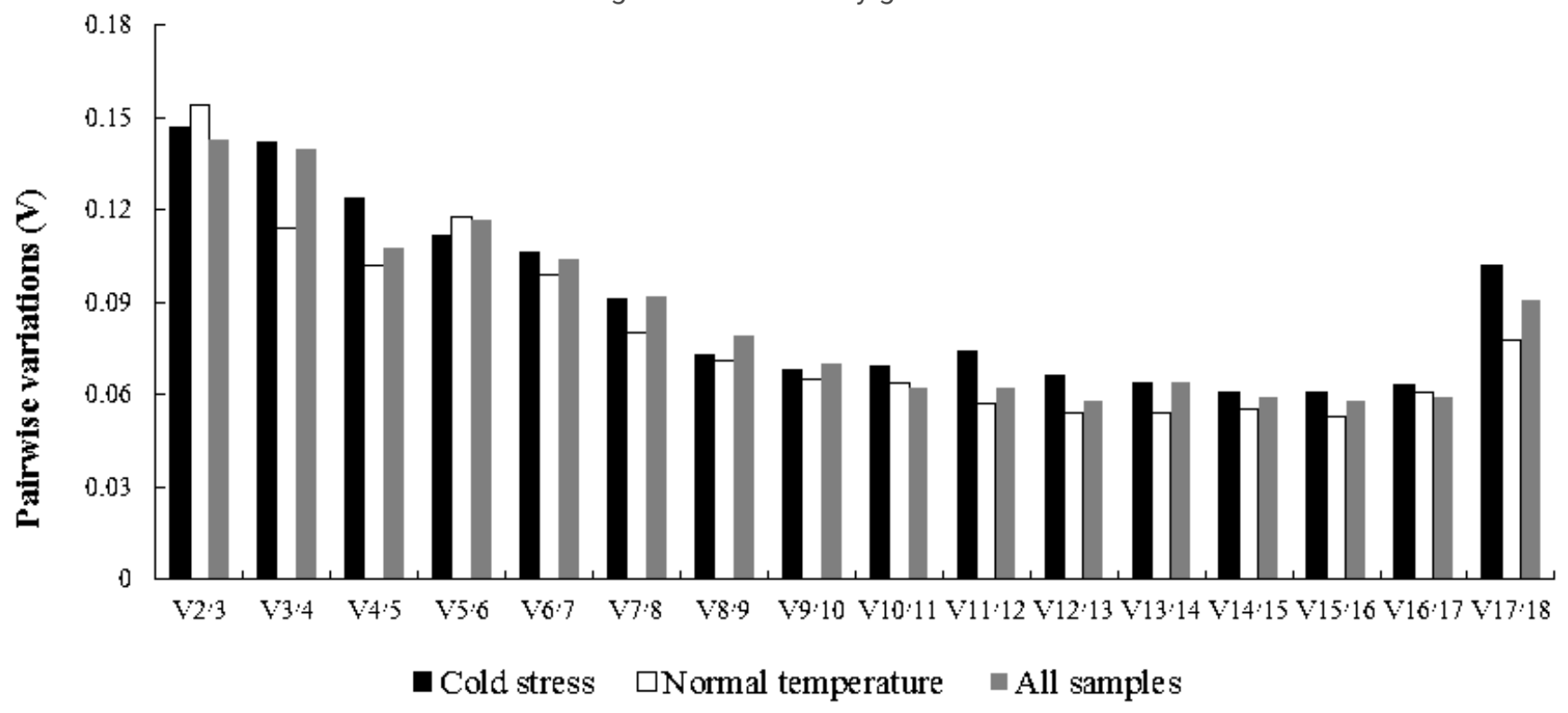

Figure 4

Pairwise variations of 18 candidate reference genes calculated by geNorm. 


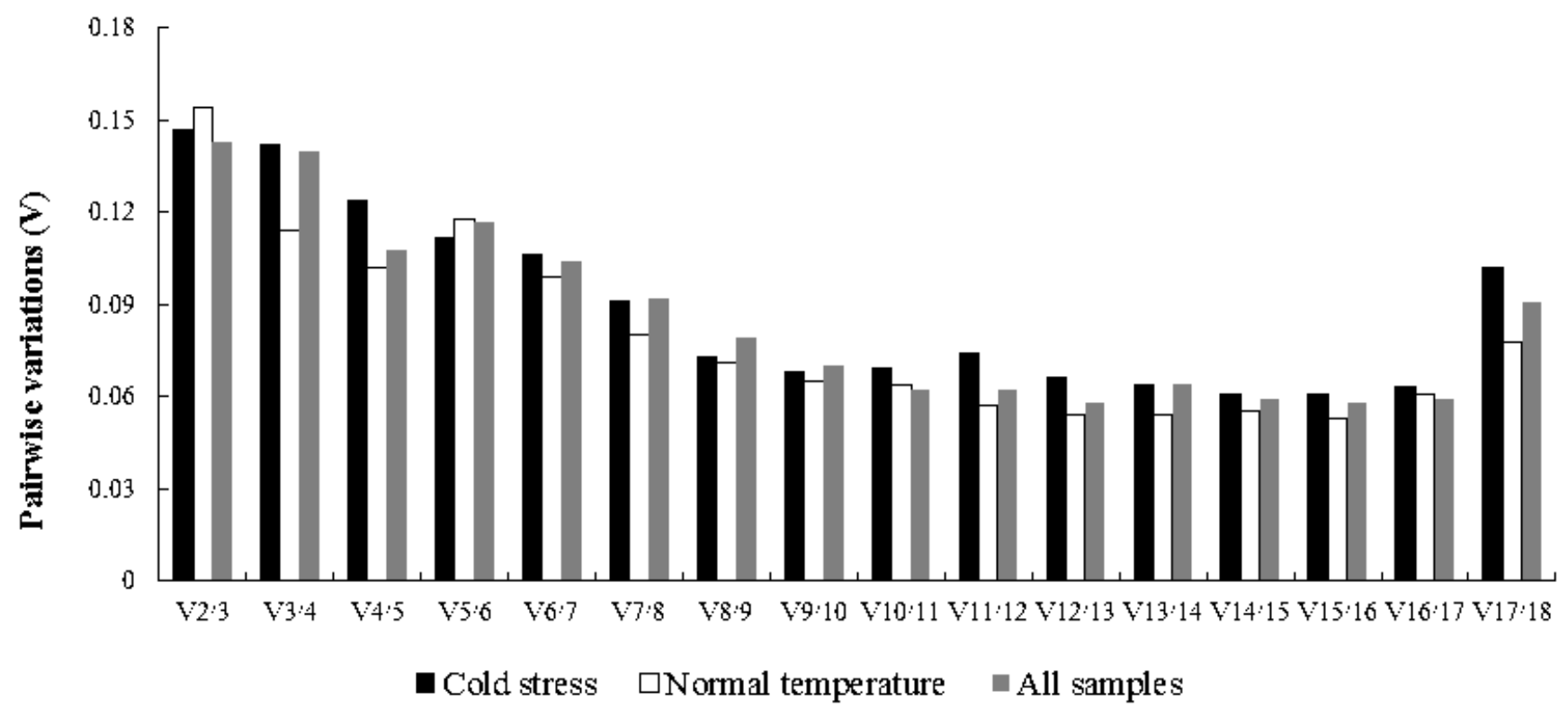

Figure 4

Pairwise variations of 18 candidate reference genes calculated by geNorm.

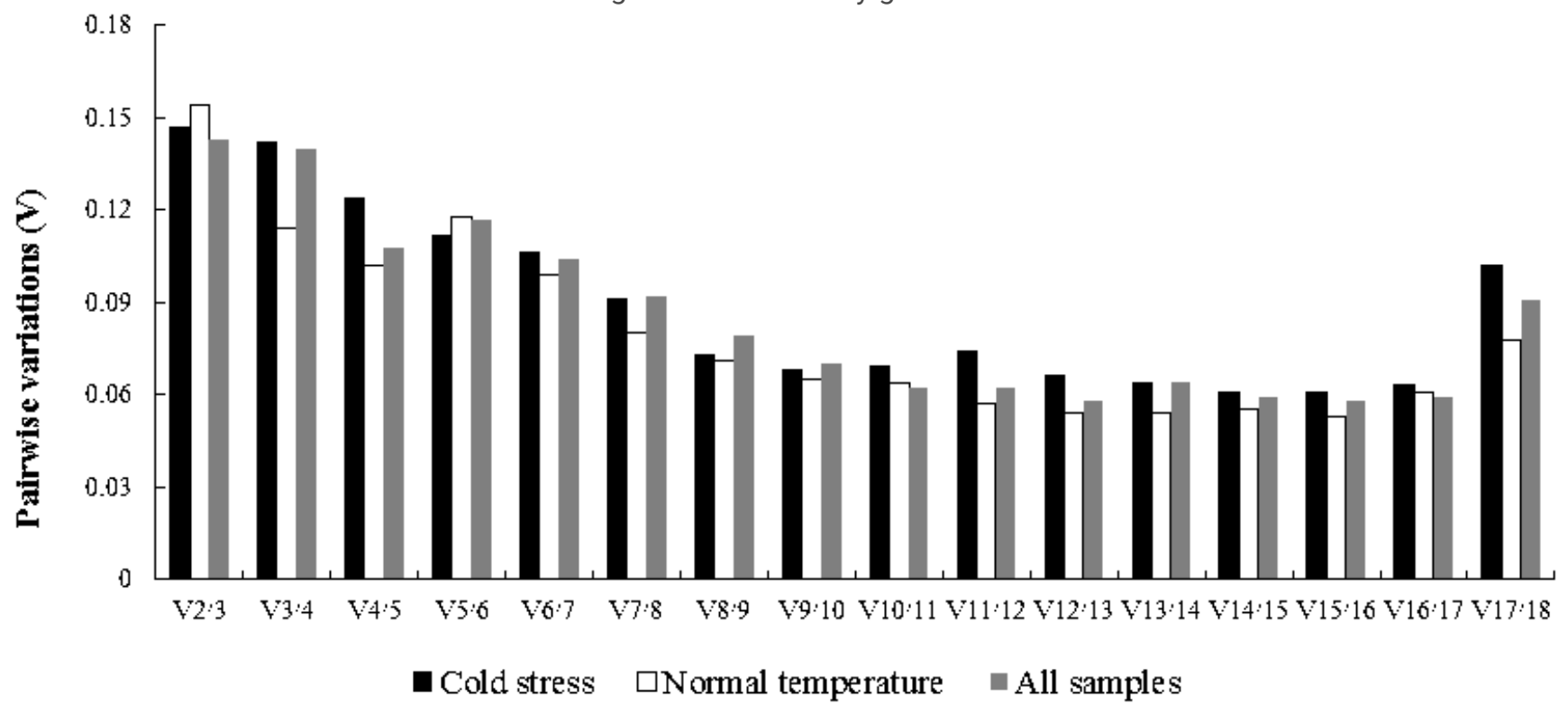

Figure 4

Pairwise variations of 18 candidate reference genes calculated by geNorm. 
P-10 cold stress (A)

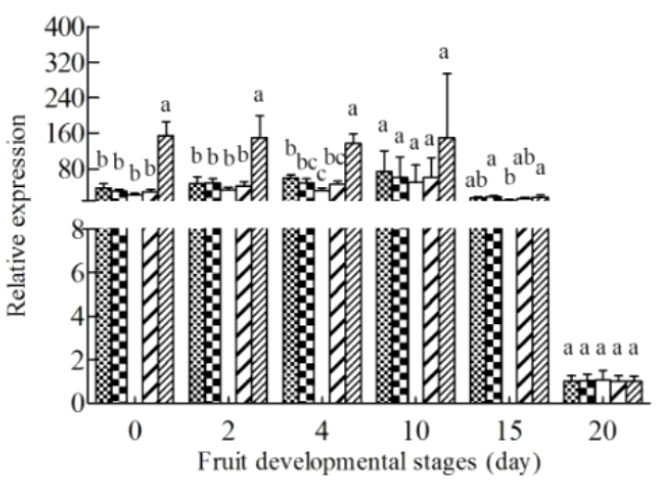

03-2 cold stress (C)
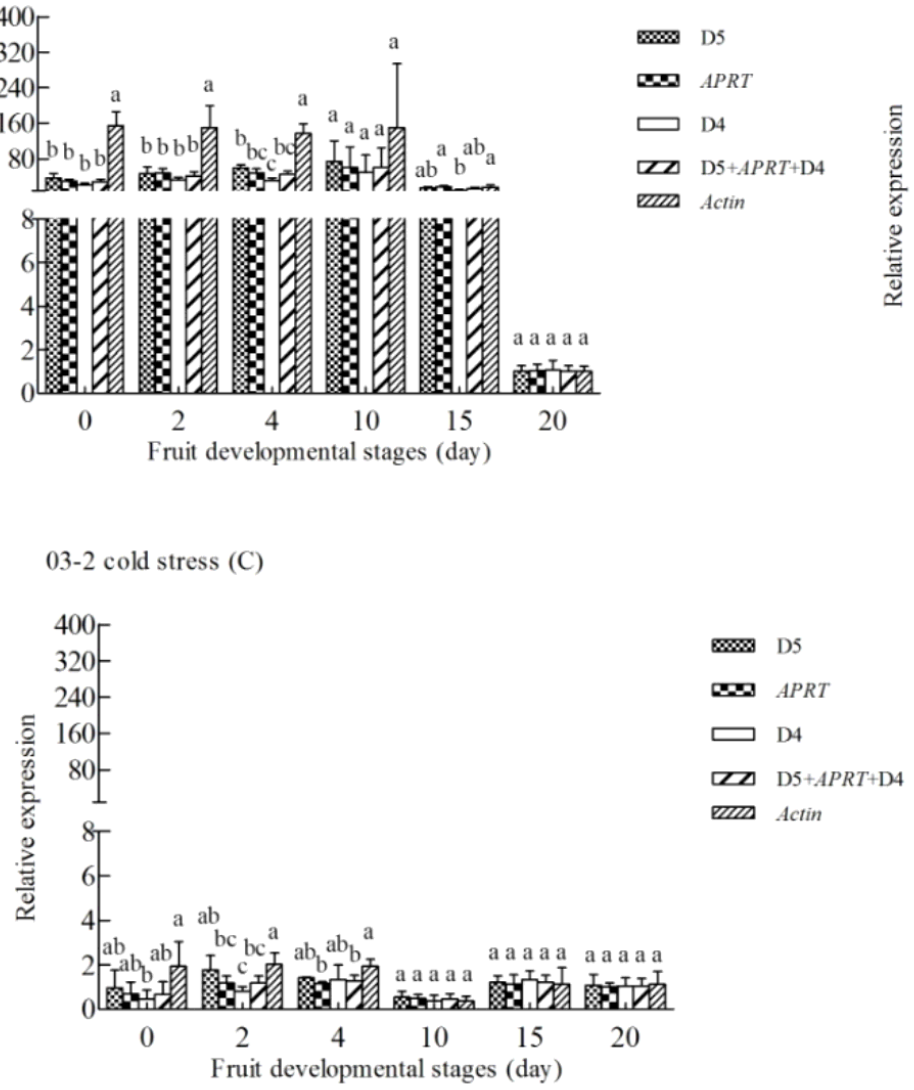

P-10 normal temperature (B)

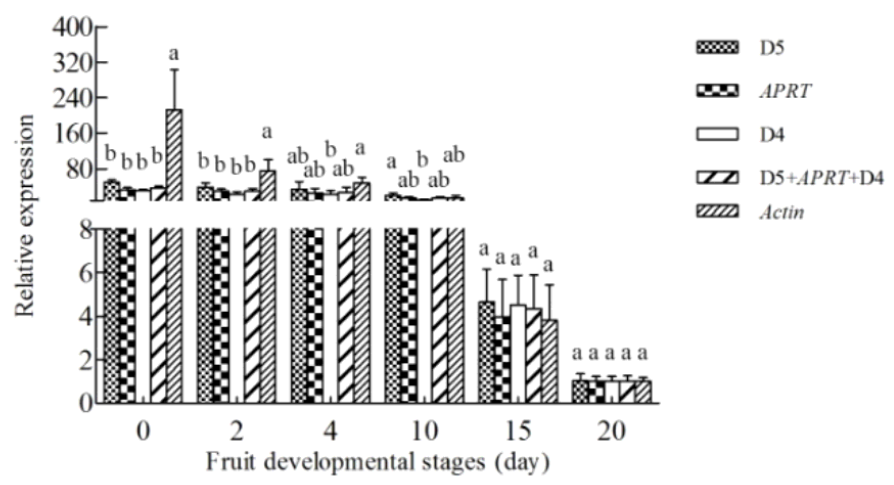

03-2 normal temperature (D)

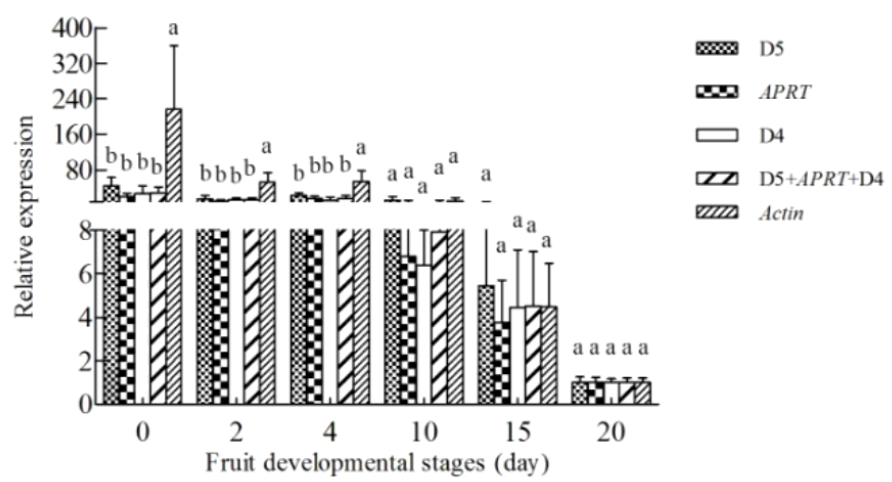

\section{Figure 5}

Expression levels of SmMsrA in ovaries or sarcocarps of P-10 and 03-2. (A-D) The expression abundance of SmMsrA calculated by D5, APRT, D4, and their combination D5+APRT+D4 and the least stable reference gene, Actin. The bars indicate the standard error, and the letters above the bars indicate significant differences $(p<0.05)$. 
P-10 cold stress (A)

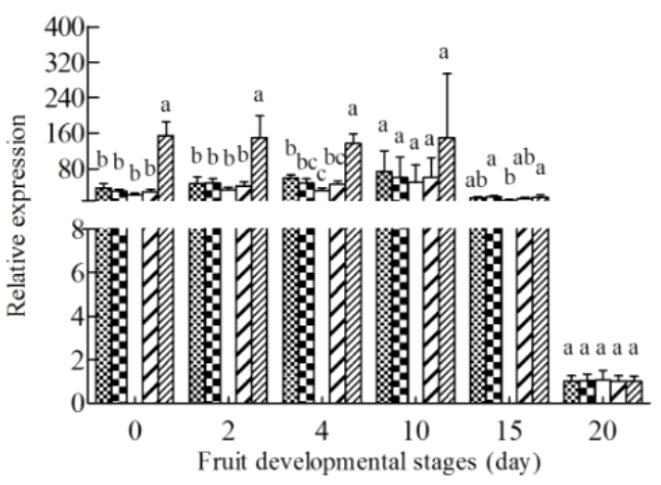

03-2 cold stress (C)
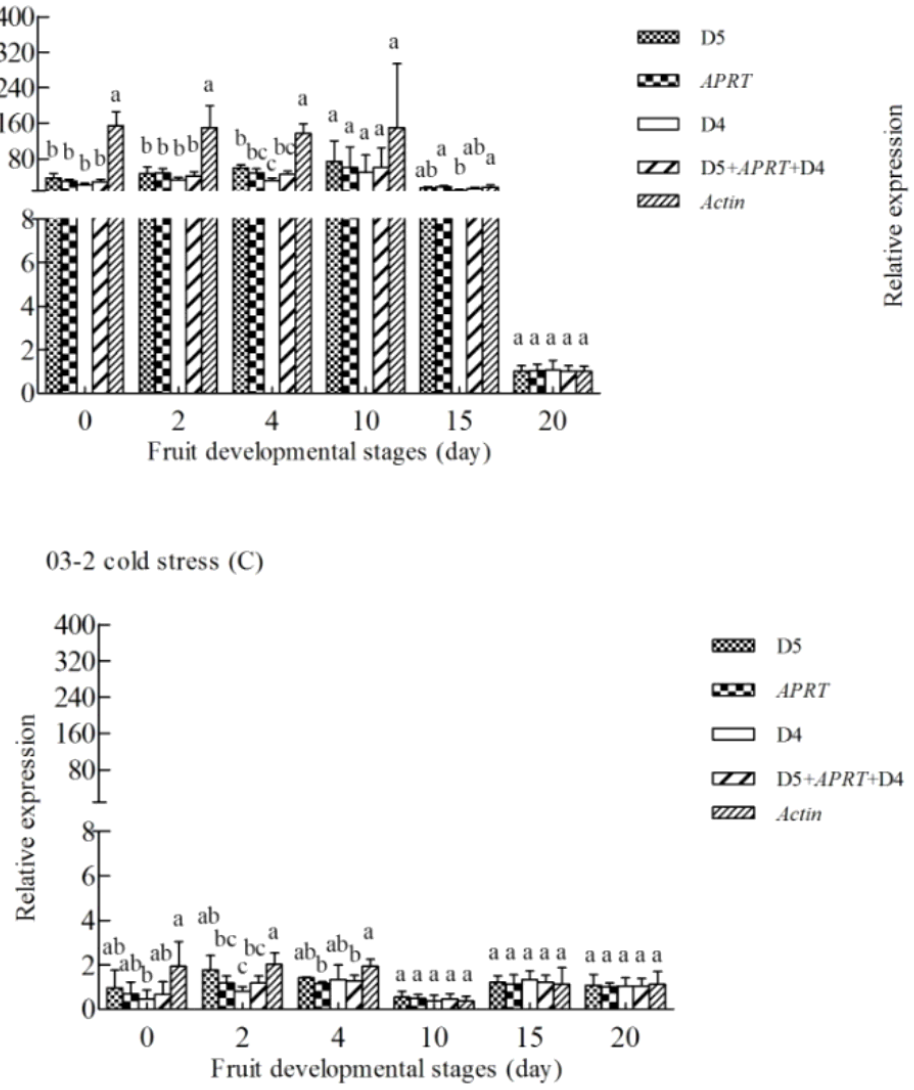

P-10 normal temperature (B)

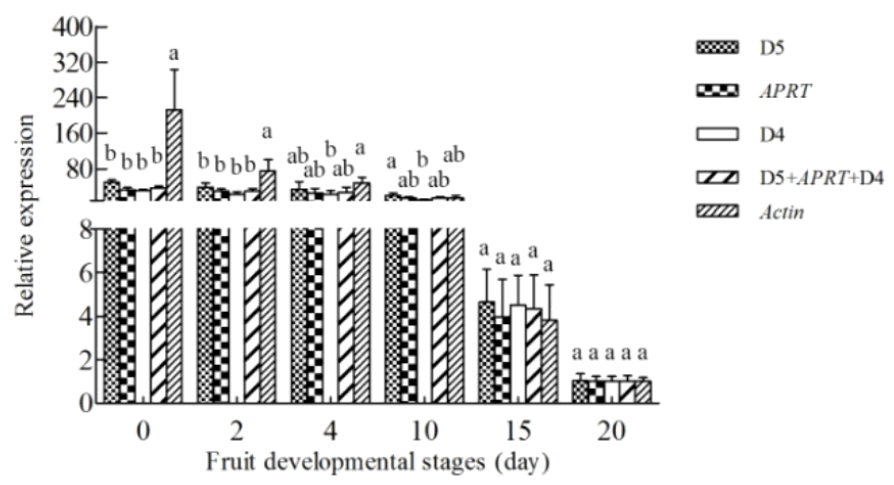

03-2 normal temperature (D)

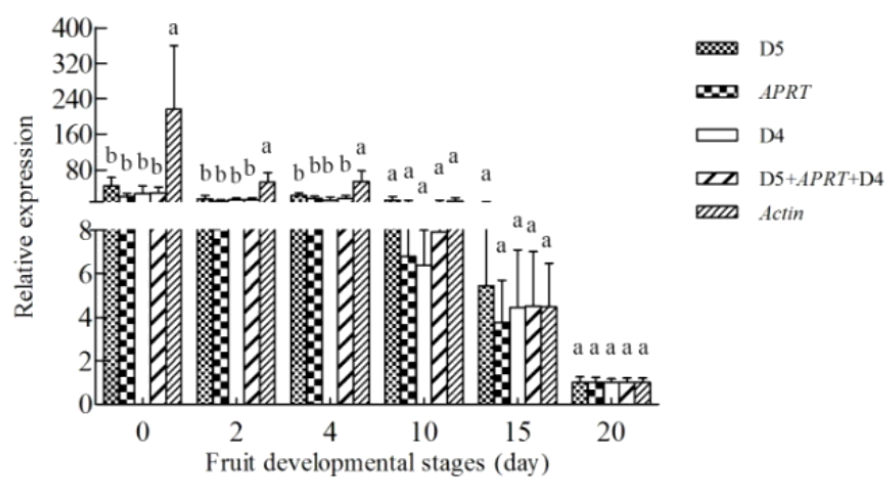

\section{Figure 5}

Expression levels of SmMsrA in ovaries or sarcocarps of P-10 and 03-2. (A-D) The expression abundance of SmMsrA calculated by D5, APRT, D4, and their combination D5+APRT+D4 and the least stable reference gene, Actin. The bars indicate the standard error, and the letters above the bars indicate significant differences $(p<0.05)$. 
P-10 cold stress (A)

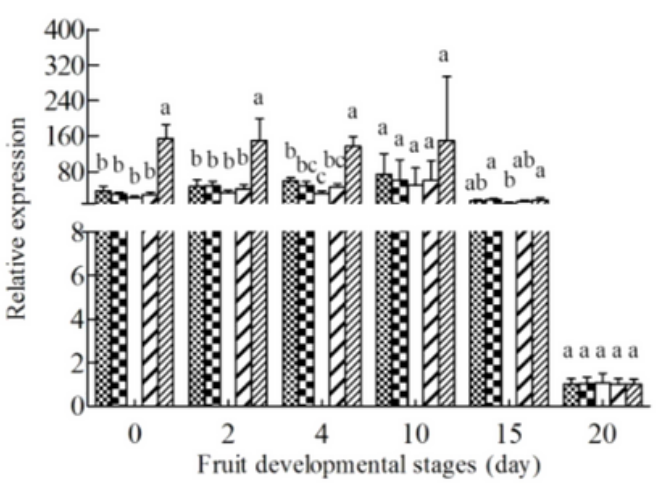

03-2 cold stress $(\mathrm{C})$

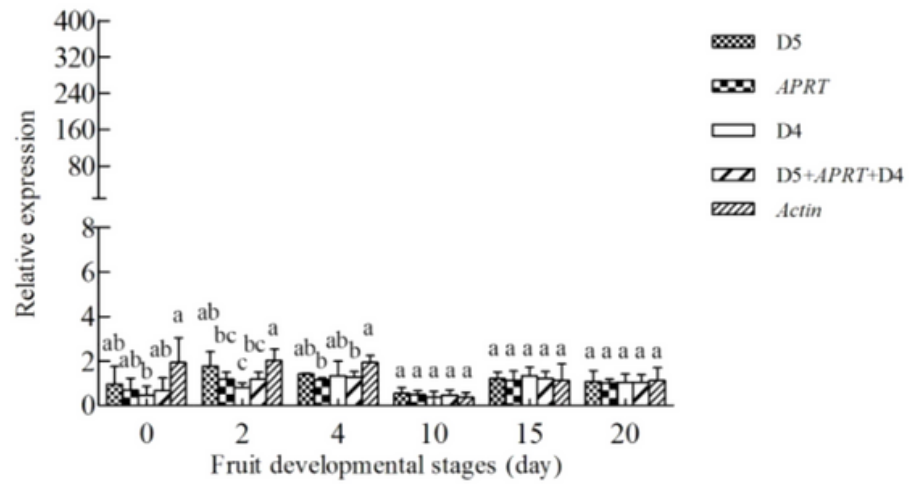

P-10 normal temperature (B)

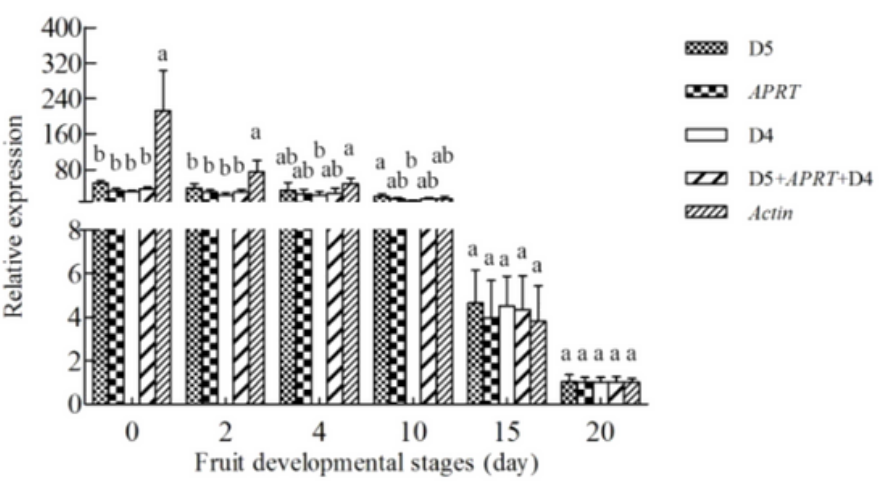

03-2 normal temperature (D)

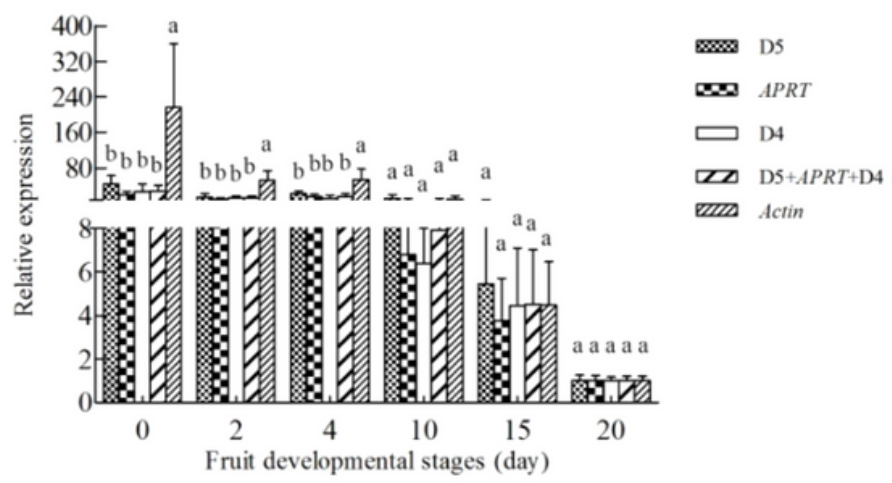

\section{Figure 5}

Expression levels of SmMsrA in ovaries or sarcocarps of P-10 and 03-2. (A-D) The expression abundance of SmMsrA calculated by D5, APRT, D4, and their combination D5+APRT+D4 and the least stable reference gene, Actin. The bars indicate the standard error, and the letters above the bars indicate significant differences $(p<0.05)$. 
P-10 cold stress (A)

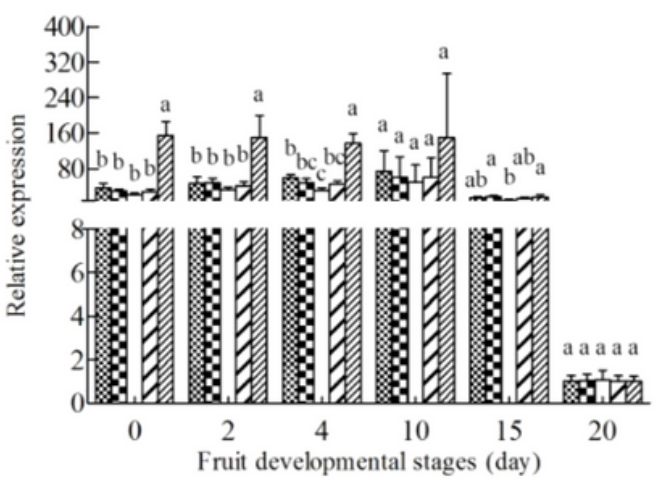

03-2 cold stress (C)

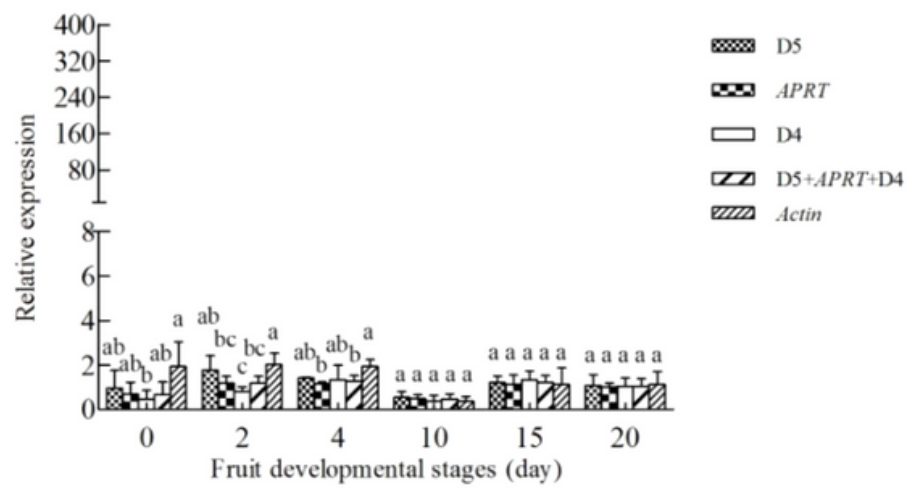

P-10 normal temperature (B)

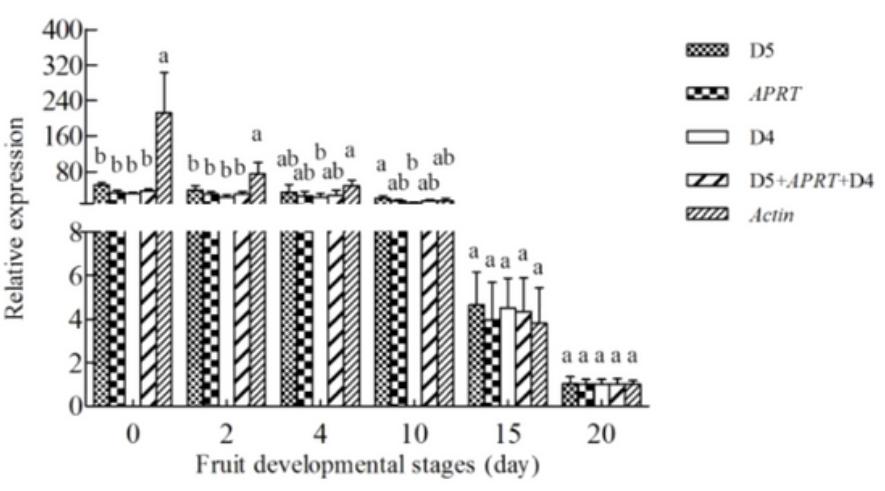

03-2 normal temperature (D)

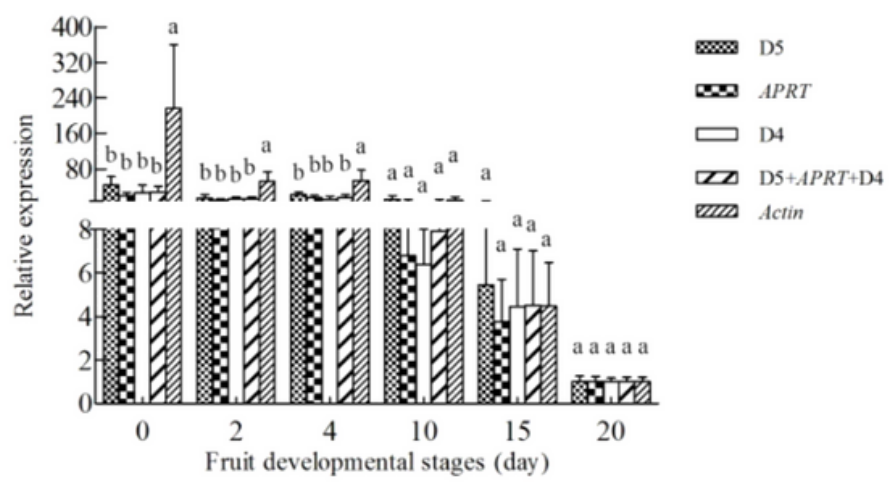

\section{Figure 5}

Expression levels of SmMsrA in ovaries or sarcocarps of P-10 and 03-2. (A-D) The expression abundance of SmMsrA calculated by D5, APRT, D4, and their combination D5+APRT+D4 and the least stable reference gene, Actin. The bars indicate the standard error, and the letters above the bars indicate significant differences $(p<0.05)$.

\section{Supplementary Files}

This is a list of supplementary files associated with this preprint. Click to download.

- ImageofgelsmodifiedbyPhotoshop.jpg

- ImageofgelsmodifiedbyPhotoshop.jpg

- ImageofgelsmodifiedbyPhotoshop.jpg

- ImageofgelsmodifiedbyPhotoshop.jpg

- SupplementaryTableS1.xIsx

- SupplementaryTables1.xlsx

- SupplementaryTableS1.xlsx

- SupplementaryTableS1.xIsx

- SupplementaryTableS2.xIsx

- SupplementaryTableS2.xlsx

- SupplementaryTableS2.xlsx

- SupplementaryTableS2.xIsx

- SupplementaryTableS3.xlsx

- SupplementaryTableS3.xIsx 
- SupplementaryTableS3.xlsx

- SupplementaryTableS3.xlsx

- Theoriginalimageofthegels.tif

- Theoriginalimageofthegels.tif

- Theoriginalimageofthegels.tif

- Theoriginalimageofthegels.tif 